\title{
Analyzing the Vegetation Parameterization in the TU-Wien ASCAT Soil Moisture Retrieval
}

\author{
Mariette Vreugdenhil, Wouter A. Dorigo, Wolfgang Wagner, Senior Member, IEEE, \\ Richard A. M. de Jeu, Sebastian Hahn, and Margreet J. E. van Marle
}

\begin{abstract}
In microwave remote sensing of the Earth's surface, the satellite signal holds information on both soil moisture and vegetation. This necessitates a correction for vegetation effects when retrieving soil moisture. This paper assesses the strengths and weaknesses of the existing vegetation correction as part of the Vienna University of Technology (TU-Wien) method for soil moisture retrieval from coarse-scale active microwave observations. In this method, vegetation is based on a multiyear climatology of backscatter variations related to phenology. To assess the plausibility of the correction method, we first convert the correction terms for retrievals from the Advanced Scatterometer (ASCAT) into estimates of vegetation optical depth $\tau_{a}$ using a water-cloud model. The spatial and temporal behaviors of the newly developed $\tau_{a}$ are compared with the optical depth retrieved from passive microwave observations with the land parameter retrieval model $\tau_{p}$. Spatial patterns correspond well, although low values for $\tau_{a}$ are found over boreal forests. Temporal correlation between the two products is high $(R=0.5)$, although negative correlations are observed in drylands. This comparison shows that $\tau_{a}$ and thus the vegetation correction method are sensitive to vegetation dynamics. Effects of the vegetation correction on soil moisture retrievals are investigated by comparing retrieved soil moisture before and after applying the correction term to modeled soil moisture. The vegetation correction increases the quality of the soil moisture product. In areas of high interannual variability in vegetation dynamics, we observed a negative impact of the vegetation correction on the soil moisture, with a decrease in correlation up to 0.4. It emphasizes the need for a dynamic vegetation correction in areas with high interannual variability.
\end{abstract}

Index Terms-Advanced Microwave Scanning RadiometerEarth Observing System (AMSR-E), Advanced Scatterometer (ASCAT), soil moisture, vegetation optical depth.

Manuscript received July 10, 2015; revised November 13, 2015; accepted December 9, 2015. This paper was supported in part by the Austrian Science Funds (FWF) through the Doctoral Program on Water Resource System of the Vienna University of Technology under Grant DK-plus W1219-N22, by the European Space Agency (ESA) through the Climate Change Initiative for Soil Moisture under Contract 4000104814/11/I-NB, and by the European Organisation for the Exploitation of Meteorological Satellites (EUMETSAT) through the Satellite Application Facility on Support to Operational Hydrology and Water Management (H-SAF)

M. Vreugdenhil is with the Centre for Water Resource Systems and the Department of Geodesy and Geoinformation, Vienna University of Technology, 1040 Vienna, Austria (e-mail: mariette.vreugdenhil@geo.tuwien.ac.at).

W. A. Dorigo, W. Wagner, and S. Hahn are with the Department of Geodesy and Geoinformation, Vienna University of Technology, 1040 Vienna, Austria (e-mail: wolfgang.wagner@geo.tuwien.ac.at).

R. A. M. de Jeu is with Transmissivity B.V.-VanderSat B.V., Space Technology Centre, 2201 DK Noordwijk, The Netherlands (e-mail: rdejeu@ transmissivity.nl).

M. J. E. van Marle is with the Cluster Group Earth and Climate, Faculty of Earth and Life Sciences, VU University Amsterdam, 1081 HV Amsterdam, The Netherlands (e-mail: m.j.e.van.marle@vu.nl).

Color versions of one or more of the figures in this paper are available online at http://ieeexplore.ieee.org.

Digital Object Identifier 10.1109/TGRS.2016.2519842

\section{INTRODUCTION}

$\mathbf{S}$ PACEBORNE microwave remote sensing has proven to provide reliable soil moisture observations on a global scale [1]-[4]. Microwaves are mainly sensitive to water content in both the soil and the vegetation, and separating these components from each other is not straightforward. Much effort has already been undertaken to correct for the impact of vegetation in the soil moisture retrieval in both active and passive microwave remote sensing [5]-[10].

Most microwave retrieval algorithms use a radiative transfer model, so-called $\tau-\omega$ model, as a basis to retrieve soil moisture. As the name suggests, a $\tau-\omega$ model is based on two parameters, namely, the optical depth $\tau$ and single scattering albedo $\omega$, which describe the attenuation and scattering by the vegetation. For example, the Vrije Universiteit AmsterdamNASA Land Parameter Retrieval Model (LPRM) [6] uses a simple radiative transfer model and a microwave polarization ratio to retrieve both soil dielectric constants and vegetation optical depth $\tau_{p}$ simultaneously from brightness temperatures measured by, e.g., Advanced Microwave Scanning RadiometerEarth Observing System (AMSR-E), AMSR2, or Soil Moisture Ocean Salinity (SMOS) microwave radiometers [6], [11], [12]. The LPRM approach is based on the assumption of polarization independence for $\tau$ and $\omega$, which makes it possible to solve $\tau_{p}$ analytically [13]. An iterative approach is used to optimize for the dielectric constant. A dielectric mixing model is employed to calculate soil moisture from the dielectric constant, using auxiliary data on soil physical properties such as particle size distribution, porosity, and wilting point from soil maps based on the FAO soil map of the world (1974-1981, scale $1: 5000000)$. An advantage of this retrieval algorithm is that, due to the analytical derivation of the optical depth, only one variable needs to be optimized: the dielectric constant.

The official SMOS retrieval algorithm uses a decision tree, based on auxiliary land cover data, to select the brightness temperature models and reference values to be used for a certain surface type. Over vegetated areas a $\tau-\omega$ model is used [5] to retrieve optical depth and soil moisture. The best-suited set of parameters, i.e., $\tau_{p}$ and soil moisture, are retrieved by minimizing a cost function between the modeled and measured brightness temperatures in an iterative approach [5].

For active microwave observations, the available algorithms use diverse approaches. To retrieve soil moisture from ERS-1 Advanced Microwave Instruments (AMI), Pulliainen et al. [14], [15] used a least-squares algorithm with a semi-empirical backscatter model, which incorporates a $\tau-\omega$ model for canopy backscatter and extinction. Promising results for soil moisture and frozen soil monitoring were found. However, a priori data on land cover and vegetation biomass are needed, making it 


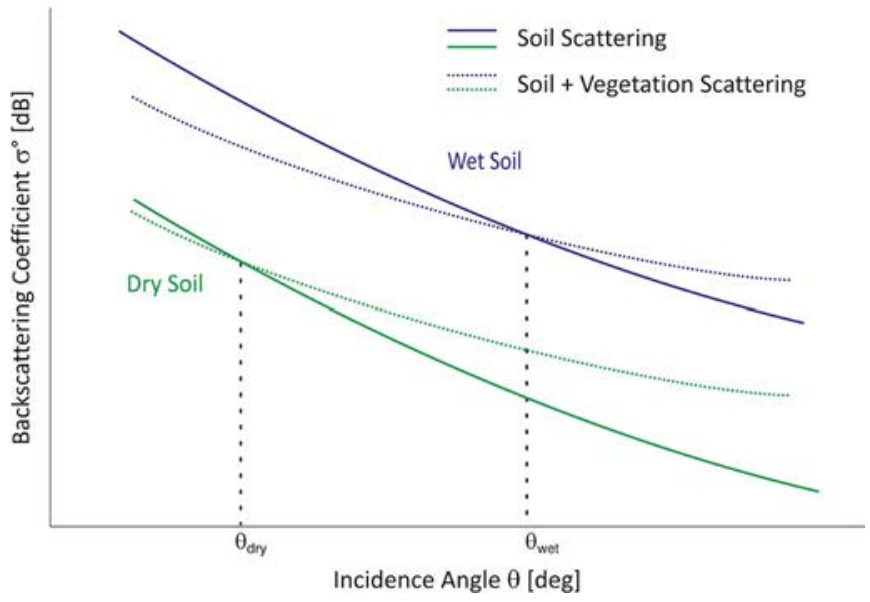

Fig. 1. Relation between backscatter and incidence angle with relation to soil moisture and vegetation (after [10]).

more difficult to apply the method on a global scale. The current retrieval algorithm for the Soil Moisture Active Passive (SMAP) scatterometer employs a time series datacube approach [7], [8], using an iterative minimization function between modeled and observed backscatter. The datacube approach leaves three unknown variables, soil moisture, roughness, and vegetation water content (VWC). Roughness and VWC will be defined using auxiliary data, whereas VWC will be retrieved from either the radar vegetation index, calculated from cross-polarization backscatter data, or from normalized difference vegetation index (NDVI). As for the SMOS algorithm, the SMAP algorithm uses auxiliary data to select the backscatter model applied to retrieve soil moisture for a certain pixel, which in this case is a land cover map.

The Vienna University of Technology (TU Wien) soil moisture retrieval algorithm [9], [10] employs a change detection method to retrieve soil moisture from scatterometers with multiincidence angle viewing capabilities, i.e., European Organisation for the Exploitation of Meteorological Satellites (EUMETSAT)'s MetOp-A and MetOp-B Advanced Scatterometers (ASCATs), and AMI onboard ERS-1 and ERS-2. One basic assumption for the change detection method is that backscatter $\left(\sigma^{\circ}\right)$, expressed in decibels, is linearly related to surface soil moisture content. Furthermore, $\sigma^{\circ}$ is strongly dependent on incidence angle $(\theta)$, and the slope and curvature of the relationship between backscatter and incidence angle $\left(\sigma^{\circ}(\theta)\right)$ are assumed affected only by vegetation density but not by changes in soil moisture (see Fig. 1). Subsequently, the slope and curvature obtained from $\sigma^{\circ}$ observations under different incidence angles are used to parameterize the vegetation for every day of the year and for every gridpoint. To account for noise in the backscatter measurements and to ensure that an entire range of incidence angles is covered, 366 slope and curvature pairs (i.e., one for each day of the year) are determined by averaging backscatter observations of several years. Currently, the entire observation period is used, i.e., 15 years for ERS and 8 years for ASCAT. Consequently, the vegetation parameter in the TU-Wien retrieval algorithm is based on climatology, which does not take into account interannual variability. A more detailed description of the algorithm can be found in Section II.
The different algorithms discussed give a brief overview of the approaches used to account for vegetation in soil moisture retrieval algorithms, as well as their strengths and weaknesses. Apart from the TU-Wien retrieval algorithm, most retrieval algorithms use auxiliary data in the form of lookup tables based on land cover maps or additional soil property data to retrieve soil dielectric constants. The TU-Wien approach provides soil moisture in relative units between $0 \%$ (dry soil surface) and $100 \%$ (saturated soil surface). It is evident that the quality of the vegetation parameterization can determine to a large extent the quality of the retrieved soil moisture since the vegetation correction can propagate an error into the soil moisture product.

Several studies have assessed the vegetation parameterization in the TU-Wien change detection method and in the VUA-NASA LPRM by comparing it with other vegetation products and indexes. Wagner et al. [16] compared backscatter observations and the slope parameter retrieved from ERS scatterometer observations to precipitation and NDVI over the Iberian Peninsula. They concluded that the temporal variation of the backscatter observations is dominated by changes in soil moisture but the slope parameter is linked to seasonal dynamics in the wet biomass of the vegetation. A lag in the maxima between the slope and NDVI was observed, attributed to the fact that the peak of photosynthetic activity and greenness of the vegetation is in early spring, whereas the peak in overall biomass is in summer.

Similar results were found for $\tau_{p}$ retrieved from AMSR-E with the VUA-NASA algorithm, where $\tau_{p}$ over drylands was found to be more sensitive to long-term precipitation variations and NDVI responded more to short-term variations [17]. This was attributed to the fact that the $\tau_{p}$ is more sensitive to woody vegetation, which can absorb water from deeper soil layers, whereas NDVI is more sensitive to canopy cover and variations in leaf foliage. In addition, a preliminary study on comparing the $\tau_{p}$ to the NDVI by [18] found that the $\tau_{p}$ and NDVI correspond better to each other over grasslands and croplands and less over shrublands and forests. The work in [19] looked at boreal forest recovery over Alaska, USA, after wild fires. The NDVI indicated initial postfire forest biomass recovery after one to three years, whereas this was three to seven years for the $\tau_{p}$. Again, the conclusion was that $\tau_{p}$ is likely more closely related to the water content in the vegetations' leafs and woody compartment, whereas the NDVI is more sensitive to chlorophyll content and leaf area index. The previous studies demonstrated that $\tau$ from microwave observations is a valuable parameter to describe vegetation characteristics, which are complementary to NDVI and other related vegetation indexes.

The use of remote sensing soil moisture products, including those retrieved with the TU-Wien algorithm, has increased significantly in the last years, ranging from improved evaporation and rainfall modeling [20]-[22] to trend analysis in droughts [23], [24] and land-atmosphere coupling models [25]. Hence, a good understanding of the vegetation parameterization in the retrieval algorithms is imperative. Errors in vegetation parameterization can propagate to the final soil moisture product. Therefore, the aim of this paper is to analyze the strengths and weaknesses of the existing vegetation correction in the TU-Wien retrieval algorithm and its effect on the final soil moisture product. In order to quantify the ability of the vegetation correction to describe the vegetation, optical depth $\tau_{a}$ is analytically retrieved from the vegetation correction using a 
water-cloud model. To asses the quality and physical meaning of this newly derived $\tau_{a}$, it is compared with the optical depth from AMSR-E $\tau_{p}$, both in the spatial and temporal domains. After looking at the quality of the vegetation parameterization and identifying areas where problems with the soil moisture retrieval might arise, the effect of the vegetation correction on the final soil moisture product is assessed. For this, the surface soil moisture product before and after applying the vegetation correction term are compared with modeled soil moisture from ERA-Land, provided by the European Centre for MediumRange Weather Forecasts (ECMWF). Here, we particularly focus on the effect that interannual variability in vegetation dynamics can have on the soil moisture retrieval.

\section{DATA SETS}

Here an overview and a short summary of the existing data sets that are used in this paper are given. The newly developed products are described in Section III.

\section{A. MetOp-A ASCAT and TU-Wien Soil Moisture Retrieval}

ASCAT is a scatterometer on board MetOp-A and MetOp-B, which are operative since 2006 and 2012, respectively. It measures vertically copolarized backscatter at incidence angles ranging from $25^{\circ}$ to $65^{\circ}$ at a frequency of $5.25 \mathrm{GHz}$ (C-Band). The MetOp satellites fly in a sun-synchronous orbit, with morning and evening overpasses at approximately 09:30 and 21:30 local time. The individual ASCAT sensors provide a global coverage approximately every two days. The spatial resolution of ASCAT backscatter observations is $25 \times 25 \mathrm{~km}^{2}$. In the TUWien retrieval algorithm, soil moisture is retrieved for every land gridpoint on a discrete global grid (WARP5 grid) with a spacing of ca. $12.5 \mathrm{~km}$.

The TU-Wien retrieval algorithm retrieves soil moisture time series with a change detection approach. One of the first steps in the algorithm is to normalize all backscatter observations taken over the entire incidence angle range to the reference incidence angle of $40^{\circ}$, resulting in the normalized backscatter $\sigma^{\circ}(40)$. The $\sigma^{\circ}(40)$ is used to calculate soil moisture on a relative scale between the historically driest and wettest observed measurements, and during this scaling, the vegetation correction of the TU-Wien retrieval algorithm is applied. The vegetation in the TU-Wien algorithm is described by way of the behavior of the slope and curvature of the backscatter signature with regard to incidence angle. Backscatter from bare soils, as a result of surface scattering, decreases strongly with increasing incidence angle, whereas volume scattering from, for example, vegetation, leads to more uniform backscatter values over all incidence angles (see Fig. 1). Hence, seasonal vegetation growth and decay changes the slope of the $\sigma^{\circ}-\theta$ curve [16], [26]. The TU-Wien algorithm uses this behavior to account for the impact of vegetation on the backscatter signal: A change in soil moisture tends to shift the curve up and down in its entirety, whereas a change in vegetation or surface roughness changes the slope of the curve (see Fig. 1). For low incidence angles, the vegetation tends to attenuate the signal from the soil surface, resulting in lower total backscatter than for bare soils. At higher incidence angles, the backscatter is higher compared with bare soil conditions, due to volume scattering from the vegetation. There are incidence angles where the attenuation of the observed bare soil backscatter and the contribution from the vegetation are in equilibrium, i.e., the so-called crossover angles (see Fig. 1). At the crossover angles, a change in backscatter is mainly a result of a change in soil moisture. These crossover angles are dependent on the soil moisture being at a lower incidence angle for dry soils than for wet soils. In [16], Wagner et al. empirically estimated these crossover angles to lie at $25^{\circ}$ for dry soils and at $40^{\circ}$ for wet soils. By converting the normalized backscatter observations to the $25^{\circ}$ crossover angle, the backscatter is only a function of soil moisture variations. To enable the retrieval of the historically driest soil conditions without the effect of vegetation attenuation or contribution, the so-called dry reference $\left(\sigma_{\mathrm{dry}}^{\circ}\right)$, the normalized backscatter is converted to the $25^{\circ}$ crossover angle where the lowest backscatter observations are related to the historically driest soil conditions. The dry reference is retrieved for every gridpoint, converting all backscatter values from $40^{\circ}$ to $25^{\circ}$, i.e., $\theta=25^{\circ}$ using a second-order Taylor expansion function as follows:

$$
\begin{aligned}
\sigma^{\circ}(\theta, t)=\sigma^{\circ}(40, t)+\sigma^{\prime}(40, & \text { DoY })(\theta-40) \\
& +\frac{1}{2} \sigma^{\prime \prime}(40, \text { DoY })(\theta-40)^{2}
\end{aligned}
$$

where $\theta$ represents the incidence angle, $\sigma^{\prime}$ is the slope, and $\sigma^{\prime \prime}$ is the curvature, which are both averaged over several years and have one value for each day of the year (DoY). At $\theta=25^{\circ}$, the average over the lowest measurements is taken, and this value is converted back to the reference incidence angle $\theta=40^{\circ}$ using the slope and curvature, with the Taylor expansion function. The use of the crossover angles and the Taylor expansion function integrate the variation of the slope, which is sensitive to vegetation water content and hence embeds a seasonal vegetation correction in the dry reference. The wet reference $\left(\sigma_{\text {wet }}^{\circ}\right)$ represents saturated soil conditions and is based on the historically wettest backscatter measurements at $\theta=40^{\circ}$. Since $\sigma^{\circ}$ is already normalized to an incidence angle of $40^{\circ}$, no conversion is needed to obtain the wet reference. Consequently, the wet reference is a constant value. In deserts, it can occur that fully saturated soil conditions are not reached or captured by ASCAT. Hence, for deserts according to the Koppen-Geiger climate classification, the wet reference is corrected based on ASCAT observations in order to provide realistic soil moisture values. Soil moisture $\left(\Theta_{a}\right)$ is then calculated by scaling $\sigma^{\circ}(40, t)$ between the dry and wet references that are for this purpose matched from their DoY to the date of the observation, as follows:

$$
\Theta_{a}(t)=\frac{\sigma^{\circ}(40, t)-\sigma_{\mathrm{dry}}^{\circ}(\mathrm{DoY})}{\sigma_{\mathrm{wet}}^{\circ}(\mathrm{DoY})-\sigma_{\mathrm{dry}}^{\circ}(\mathrm{DoY})} .
$$

Soil moisture is retrieved on specific days for specific years, whereas the dry and wet reference are a product of the slope and curvature, for which only 366 values are available, i.e., one value for every day of the year. Consequently, the vegetation correction, which is intrinsically incorporated in the computation of the dry and wet reference and based on the slope and curvature, is not varying on an interannual basis. The difference between the $\sigma_{\mathrm{dry}}^{\circ}$ and $\sigma_{\text {wet }}^{\circ}$ is the sensitivity $\left(\Delta \sigma^{\circ}\right)$ to changes in surface soil moisture content (see Fig. 2), i.e.,

$$
\Delta \sigma^{\circ}(\mathrm{DoY})=\sigma_{\text {wet }}^{\circ}(\mathrm{DoY})-\sigma_{\mathrm{dry}}^{\circ}(\mathrm{DoY}) .
$$




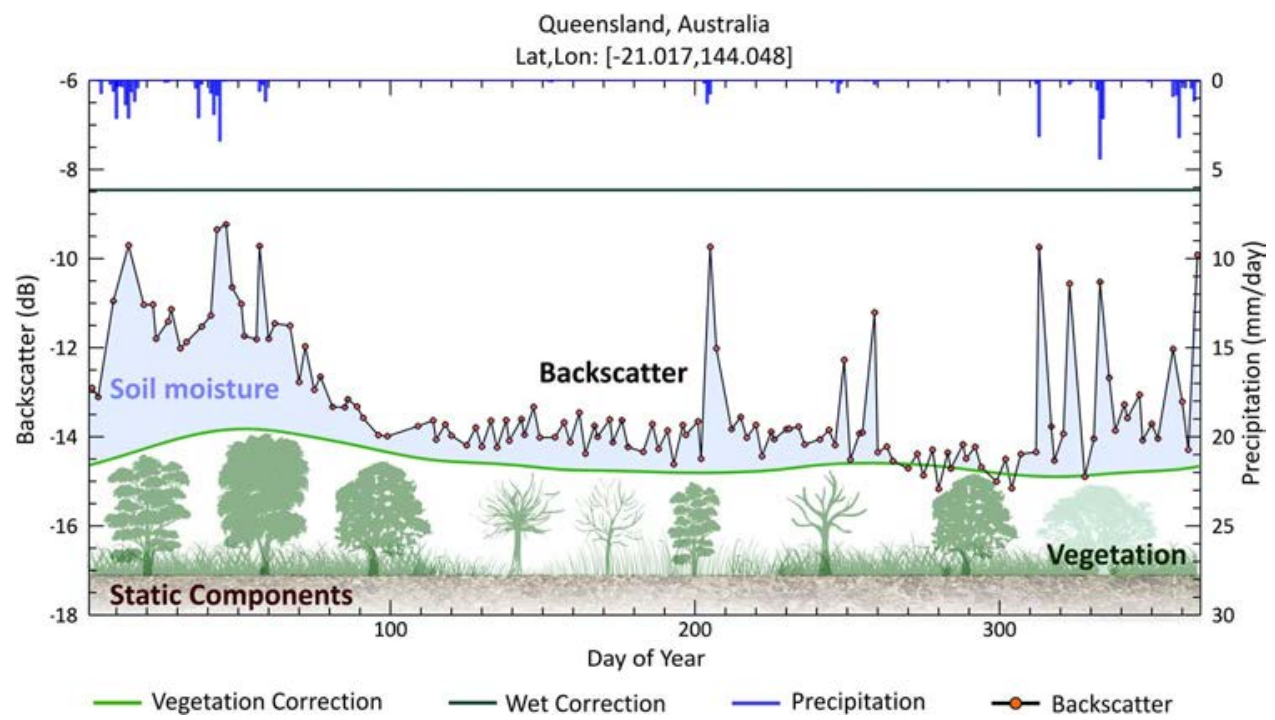

Fig. 2. Three components of the backscatter signal, the dry reference, wet reference, and observed backscatter from the TU-Wien change detection algorithm for a grid point in Queensland, Australia.

Since backscatter in decibels has been found to be linearly related to soil moisture, and backscatter noise is independent of the absolute $\sigma^{\circ}$ when expressed in decibels, all the calculations within the TU-Wien retrieval algorithm are done in the decibel domain.

\section{B. AMSR-E and the LPRM Vegetation Optical Depth $\left(\tau_{p}\right)$ Retrieval}

There are several $\tau_{p}$ products available from passive microwave observations. In this paper, $\tau_{p}$ retrieved from AMSR-E passive microwave observations at $6.9 \mathrm{GHz}$ with the VUA-NASA LPRM is used. The VUA-NASA retrieval model is developed by the VU University Amsterdam in collaboration with NASA, and uses a radiative transfer model to solve for soil moisture and $\tau_{p}$ simultaneously [27]. In LPRM, $T_{b}$ is represented by the following radiative transfer equation [28]:

$$
\begin{aligned}
T_{b, l}=T_{s} e_{r, l} \gamma+(1-\omega) & T_{c}(1-\gamma) \\
& +\left(1-e_{r, l}\right)(1-\omega) T_{c}(1-\gamma) \gamma
\end{aligned}
$$

where 1 refers to the polarization, $T_{s}$ and $T_{c}$ give the surface and canopy temperature, $\omega$ represents the single scattering albedo, $e_{r}$ gives the emissivity of the soil, and $\gamma$ is given by

$$
\gamma=e^{-\frac{\tau}{\cos \theta}}
$$

In LPRM, $T_{s}$ and $T_{c}$ are assumed equal, and $T_{s}$ is separately retrieved from Ka-band observations according to [29]. $\tau_{p}$ is derived analytically directly from the $\tau-\omega$ model [13] and is the basis of LPRM. Using (4), optical depth and soil emissivity are optimized against $T_{b}$. The soil emissivity is related to soil moisture using soil physical properties from FAO soil maps and a dielectric mixing model. In LPRM, both roughness and the single scattering albedo are assumed constant.

The $\tau_{p}$ is considered linearly related to the above-ground biomass water content, i.e., water content in the woody and nonwoody components of the vegetation [17], [30]. Care needs to be taken when interpreting $\tau_{p}$ data over areas with open water [31] and with radio frequency interference (RFI). Only ascending nighttime observations are used to meet the assumption $T_{s}=T_{c}$. In addition, $\tau_{p}$ is masked when the RFI flag $>2$. $\tau_{p}$ data cannot be computed when the soil is snow covered or frozen. $\tau_{p}$ data are available globally approximately every two days on a $0.25^{\circ}$ grid.

In this paper, $\tau_{p}$ time series from 2007 to 2011 are used. Since $\tau_{a}$ is based on a climatology, averaged over several years of data, we computed the climatology of $\tau_{p}$ by averaging the data for every DoY from 2007 to 2011. In addition, a smoothing with a window of 16 days was applied to better correspond to the $\tau_{a}$, which is calculated with a time window ranging from 2 to 12 weeks. Since the $\tau_{a}$ is available on a $12.5-\mathrm{km}$ discrete global grid (WARP5 grid), it was resampled to the spatial grid of $\tau_{p}, 0.25^{\circ}$, by taking the median of the $\tau_{a}$ values of which the center of the gridpoint falls within a $\tau_{p}$ gridpoint.

\section{Ancillary Data}

ERA-Land surface soil moisture $\left(\Theta_{\mathrm{ERA}}\right)$ data from the ECMWF [32], [33] is used as a reference to analyze the effect of the vegetation correction on the soil moisture retrieval. Soil moisture of the first soil layer $(0-7 \mathrm{~cm})$ was extracted for the period 2007-2011. $\Theta_{\mathrm{ERA}}$ is available every $6 \mathrm{~h}$, and daily means are calculated by averaging all observations within one day.

In addition, Global Land Data Assimilation System (GLDAS2-Noah) rainfall data at a $0.25^{\circ}$ spatial sampling is used [34] in the time series plots. The data are available on a 3-h interval and is resampled to daily average rainfall in millimeters for this paper.

Results of the performed analysis are spatially compared with an updated Koppen-Geiger climate classification map from [35], based on temperature and precipitation observations for the period 1951-2000 (see Fig. 3). An overview of the different Koppen-Geiger climate classes (KGCs) can be found in Table I.

For the modeling of bare soil backscatter, soil data from the Harmonized World Soil Data set (HWSD) are used [36]. The 


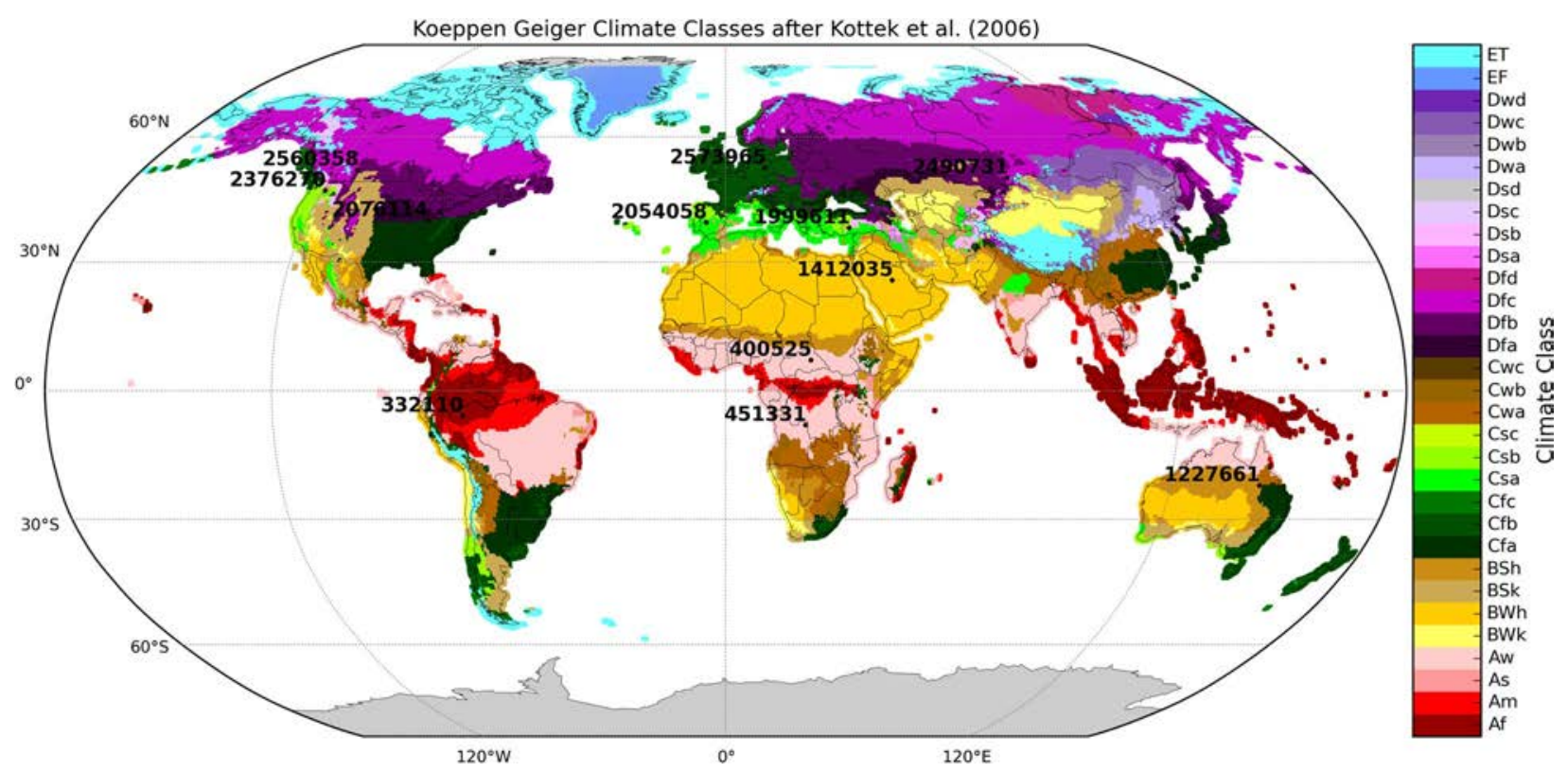

Fig. 3. Map of KGCs with the gridpoint locations.

TABLE I

KGCS AFTER [35]

\begin{tabular}{|c|c|c|c|}
\hline Climate & Type & Class (Precipitation) & Subclass (Temperature) \\
\hline Equatorial Climate & $\begin{array}{l}\text { Af } \\
\text { Am } \\
\text { As } \\
\text { Aw }\end{array}$ & $\begin{array}{l}\text { Rainforest } \\
\text { Monsoon } \\
\text { Savanna with dry summer } \\
\text { Savanna with dry winter }\end{array}$ & \\
\hline Arid Climate & $\begin{array}{l}\mathrm{BW} \\
\mathrm{BS}\end{array}$ & $\begin{array}{l}\text { Desert } \\
\text { Steppe }\end{array}$ & $\begin{array}{l}\mathrm{h}=\text { Hot arid } \\
\mathrm{k}=\text { Cold arid }\end{array}$ \\
\hline Warm Temperate Climate & $\begin{array}{l}\mathrm{Cs} \\
\mathrm{Cw} \\
\mathrm{Cf}\end{array}$ & $\begin{array}{l}\text { With dry summer } \\
\text { With dry winter } \\
\text { Fully humid }\end{array}$ & \multirow{2}{*}{$\begin{array}{l}\mathrm{a}=\text { Hot summer } \\
\mathrm{b}=\text { Warm summer } \\
\mathrm{c}=\text { Cool summer } \\
\mathrm{d}=\text { Extremely continental }\end{array}$} \\
\hline Snow Climate & $\begin{array}{l}\text { Ds } \\
\text { Dw } \\
\text { Df }\end{array}$ & $\begin{array}{l}\text { With dry summer } \\
\text { Dry Winter } \\
\text { Fully humid }\end{array}$ & \\
\hline Polar Climate & $\begin{array}{l}\text { ET } \\
\text { EF }\end{array}$ & $\begin{array}{l}\text { Tundra } \\
\text { Frost }\end{array}$ & \\
\hline
\end{tabular}

HWSD provides standardized soil property data on a 1-km grid, based on regional and national data. In addition, percent tree cover data [37] from Landsat images from the year 2000 is used to select nonvegetated areas. All data were resampled to the spatial resolution of AMSR-E, $0.25^{\circ}$.

\section{Methods And Metrics}

This section describes the methods that are used to retrieve new products, i.e., the optical depth from ASCAT observations, and the methods and metrics applied to assess the existing and newly derived products.

\section{A. Vegetation Optical Depth Retrieval $\left(\tau_{a}\right)$ From ASCAT Observations}

For the retrieval of optical depth from ASCAT backscatter observations, we used the TU-Wien retrieval algorithm and a water-cloud model [38]-[40], which describes the total backscatter, in the power domain, as

$$
\sigma^{\circ}(\theta)=C \cdot \cos \theta\left(1-\gamma^{2}\right)+\sigma_{s}^{\circ}(\theta) \gamma^{2}
$$

where $\sigma^{\circ}(\theta)$ and $\sigma_{s}^{\circ}(\theta)$ represent the total backscatter coefficient and the backscatter coefficient of the soil surface in the power domain, $C$ is a parameter related to the single scattering albedo $\omega$, which for small isotropic scatterers take the value of $3 \omega / 4$, but in this case, can take any value since it does not affect the final calculation of $\tau_{a} \cdot \gamma^{2}$, i.e., the two-way vegetation transmissivity, is given as

$$
\gamma^{2}=e^{-\frac{2 \tau}{\cos \theta}}
$$

The first term on the right-hand side of (6) describes the contribution from the vegetation layer, and the second term, i.e., the soil surface contribution, is reduced by vegetation attenuation. 
TABLE II

BARE Soll Backscatter ANd Roughness MeASurements From Literature

\begin{tabular}{|c|c|c|c|c|c|c|c|c|c|}
\hline \multirow{2}{*}{$\begin{array}{c}\text { Sensor, freq., } \\
\text { inc. angle }\end{array}$} & $\sigma_{d r y}$ & $\sigma_{w e t}$ & $\Delta \sigma_{s}$ & \multirow{3}{*}{$\begin{array}{c}\Delta \sigma_{s} \\
{\left[\mathrm{~m}^{2} \mathrm{~m}^{-2}\right]} \\
0.7\end{array}$} & \multirow{2}{*}{\multicolumn{2}{|c|}{$\frac{s}{[\mathrm{~cm}]}$}} & \multirow{2}{*}{$\begin{array}{l}\mathbf{s m} \\
{\left[\mathrm{m}^{2} \mathrm{~m}^{-2}\right]}\end{array}$} & \multirow{2}{*}{ Landuse/Tillage } & \multirow{2}{*}{ Study } \\
\hline & \multicolumn{3}{|c|}{$[\mathrm{dB}]$} & & & & & & \\
\hline \multirow{2}{*}{ MAS, $4.25 \mathrm{GHz}, 20^{\circ}$} & -10 & -2 & 8 & & 4.1 & \multirow{2}{*}{$b$} & \multirow{2}{*}{$0.05-0.40$} & \multirow{2}{*}{$\begin{array}{l}\text { ploughed bare soil } \\
\text { dragged bare soil }\end{array}$} & \multirow{2}{*}{ [44]* } \\
\hline & -15 & -7 & 8 & 0.16 & 1.1 & & & & \\
\hline MAS, $4.25 \mathrm{GHz}, 10^{\circ}$ & - & - & 7.5 & - & $1.1-4.1$ & $b$ & $0.05-0.35$ & "”' & [44] \\
\hline \multirow{2}{*}{ MAS, $5.25 \mathrm{GHz}, 30^{\circ}$} & -11 & -1 & 10 & 0.71 & 4.1 & \multirow{2}{*}{$b$} & $0.08-0.40$ & chiseled bare soil & \multirow{2}{*}[45]{$*$} \\
\hline & -17 & -8 & 9 & 0.14 & 1.1 & & $0.07-0.35$ & dragged bare soil & \\
\hline $\mathrm{SAR}, 5.3 \mathrm{GHz}, 23^{\circ}$ & - & - & 5.5 & - & $0.5-2.5$ & $a$ & $0.05-0.3$ & rolled, harrowed, disked bare soil & [67] \\
\hline $\mathrm{SAR}, 5.3 \mathrm{GHz}, 23^{\circ}$ & -18 & -8 & 10 & 0.14 & $0.2-0.5$ & $a$ & $0.05-0.35$ & planting row structure & {$[46] *$} \\
\hline $\mathrm{SAR}, 5.3 \mathrm{GHz}, 23^{\circ}$ & -7 & 0.5 & 7.5 & 0.92 & - & & $0.05-0.40$ & bare soil & {$[68]$} \\
\hline- & \multicolumn{3}{|c|}{-} & - & $0.49-3.43$ & $b$ & - & pasture - bare soil & [69] \\
\hline- & \multicolumn{3}{|c|}{-} & - & $0.03-4.00$ & $a$ & - & $\begin{array}{l}\text { wheat sowing fields prepared three } \\
\text { months earlier - ploughed bare soil }\end{array}$ & {$[47]$} \\
\hline- & \multicolumn{3}{|c|}{-} & - & $0.32-3.03$ & $c$ & - & - & {$[70]$} \\
\hline- & \multicolumn{3}{|c|}{-} & - & $0.02-0.90$ & $a$ & - & natural grassland/pasture & [71] \\
\hline- & \multicolumn{3}{|c|}{-} & - & $0.20-2.45$ & $b$ & - & bare soil & {$[72]$} \\
\hline- & \multicolumn{3}{|c|}{-} & - & $0.70-4.70$ & $c$ & - & rolled - ploughed & [49] \\
\hline- & \multicolumn{3}{|c|}{-} & - & $1.47-4.33$ & $a$ & - & rolled seedbed - ploughed & [73] \\
\hline- & \multicolumn{3}{|c|}{-} & - & $0.60-3.08$ & $a$ & - & rangeland & {$[48]$} \\
\hline - & \multicolumn{3}{|c|}{-} & - & $0.64-1.99$ & $a$ & - & rangeland & [74] \\
\hline
\end{tabular}

\footnotetext{
* Estimated from figures

a: needle-pin profilometer

$b$ : photography/spraypainting

$c$ : laser profile
}

Optical depth from active microwave observations is calculated by ingesting the $\sigma_{\text {dry }}^{\circ}$ and $\sigma_{\text {wet }}^{\circ}$ (converted from $\mathrm{dB}$ to $\mathrm{m}^{2} \mathrm{~m}^{-2}$ ), into the water-cloud model. Because the dry and wet references intrinsically incorporate changes in vegetation density, a change in sensitivity $\left(\Delta \sigma^{\circ}\right)$ is directly related to $\tau_{a}$, which can be mathematically illustrated using the water-cloud model by combining (6) and (7) and calculating the sensitivity $\Delta \sigma^{\circ}$ in $\mathrm{m}^{2} \mathrm{~m}^{-2}$

$$
\begin{aligned}
\Delta \sigma^{\circ}(\mathrm{DoY}) & =\left(\sigma_{s, \text { wet }}-\sigma_{s, \mathrm{dry}}\right) e^{-\frac{2 \tau_{a}(\mathrm{DoY})}{\cos \theta}} \\
& =\Delta \sigma_{s}^{\circ} e^{-\frac{2 \tau_{a}(\mathrm{DoY})}{\cos \theta}}
\end{aligned}
$$

which can be solved for $\tau_{a}$ as

$$
\tau_{a}(\mathrm{DoY})=\frac{\cos \theta}{2} \ln \frac{\Delta \sigma_{s}^{\circ}}{\Delta \sigma^{\circ}(\mathrm{DoY})}
$$

where $\Delta \sigma^{\circ}$, in $\mathrm{m}^{2} \mathrm{~m}^{-2}$, is the sensitivity calculated from $\sigma_{\text {dry }}^{\circ}$ and $\sigma_{\text {wet }}^{\circ}$, and $\Delta \sigma_{s}^{\circ}$, also in the linear domain, represents the maximum range in backscatter values over bare soils related to a change in soil moisture only and is assumed constant through time. $\Delta \sigma_{s}^{\circ}$ cannot be retrieved directly, but for this paper, is estimated from backscatter observations over nonvegetated areas and modeled using the latest version of the Integrated Equation Model (IEM) [41]. The calculation of the $\Delta \sigma_{s}^{\circ}$ and results are discussed in the following sections. Negative $\tau_{a}$ values occur when $\Delta \sigma^{\circ}$ exceeds $\Delta \sigma_{s}^{\circ}$. For these areas, $\tau_{a}$ is set to $0 . \tau_{a}$ is available for every day of the year and is masked when no data for $\tau_{p}$ is available to account for snow-covered or frozen soil.

\section{B. Bare Soil Backscatter Estimation and Sensitivity Analysis}

In order to calculate $\tau_{a}$, the sensitivity of backscatter to changes in soil moisture in bare soils needs to be estimated. As a first step, we try to estimate this based on ASCAT observations by identifying areas that are not covered by any high vegetation and looking at the driest (lowest) measurements over these gridpoints during periods with minimum vegetation. Bare soil areas are classified as areas with a percent tree cover [37] of less than $10 \%$, and optical depth values from AMSR-E of less than 0.20. A literature study is performed on studies that measured backscatter over bare soils to obtain an average value for the backscatter sensitivity to soil moisture changes. These studies demonstrate that sensitivity of backscatter to changes in soil moisture varies from about 5.5 to $10 \mathrm{~dB}$ depending on the change in soil moisture. These values for $\Delta \sigma_{s}$ have been found for different sensor configurations, for a large diversity of soil types and rms heights of random soil roughness $(s)$ (see Table II). This leads to our assumption that one value for $\Delta \sigma_{s}^{\circ}$ can be set.

When $\sigma_{s, \text { dry }}$ and $\Delta \sigma_{s}^{\circ}$ in $\mathrm{dB}$ are known, $\Delta \sigma_{s}^{\circ}$ can easily be calculated in $\mathrm{m}^{2} \mathrm{~m}^{-2}$, as follows:

$$
\begin{aligned}
\Delta \sigma_{s}^{\circ}[\mathrm{dB}] & =10 \cdot \log \sigma_{s, \text { wet }}-10 \cdot \log \sigma_{s, \mathrm{dry}}^{\circ} \\
\Delta \sigma_{s}^{\circ}\left[\mathrm{m}^{2} \mathrm{~m}^{-2}\right] & =\sigma_{s, \mathrm{dry}} \cdot 10^{\frac{\Delta \sigma_{s}^{\circ}[\mathrm{dB}]}{10}}-\sigma_{s, \mathrm{dry}}\left[\mathrm{m}^{2} \mathrm{~m}^{-2}\right] \\
& =\left(10^{\frac{\Delta \sigma_{s}^{\circ}[\mathrm{dB}]}{10}}-1\right) \cdot \sigma_{s, \mathrm{dry}}^{\circ}\left[\mathrm{m}^{2} \mathrm{~m}^{-2}\right] .
\end{aligned}
$$

Since there are limited nonvegetated gridpoints in tropical, temperate, and cold climate classes, and experiments are mainly done with a different configuration than that of ASCAT, $\sigma_{s \text {, dry }}^{\circ}$ and $\Delta \sigma_{s}^{\circ}$ are also modeled using the integral equation model 
(IEM) [41]. The IEM is the most commonly used theoretical model for modeling backscatter from bare soils. It combines the Kirchhoff and small perturbation methods and is applicable to a large range of surface roughness scales and frequencies. It describes the backscatter behavior of a random rough bare surface. A detailed description can be found in [41]. Since bare soil backscatter is sensitive to soil surface roughness and soil properties a range of root mean square (rms) heights of the surface have been used. To get representative average values for $\sigma_{s, \mathrm{dry}}^{\circ}$ and $\Delta \sigma_{s}^{\circ}$, backscatter is modeled for every gridpoint using the respective soil texture for that gridpoint. Subsequently, a global weighted average based on soil texture is calculated for $\sigma_{s, \text { dry }}^{\circ}$ and $\Delta \sigma_{s}^{\circ}$. Only $s$ is varied between 0.5 and $2.5 \mathrm{~cm}$ in the modeling since soil moisture is more than ten times as sensitive to errors in $s$ than correlation length [42]. In [43], the correlation length was found to vary between 2 and $20 \mathrm{~cm}$ for agricultural fields. Based on these findings, correlation length is kept constant, set to a value of $10 \mathrm{~cm}$. Final values for $\sigma_{s, \mathrm{dry}}^{\circ}$ and $\Delta \sigma_{s}^{\circ}$ are set based on observations and modeling.

Furthermore, to take into account the effect of $\Delta \sigma_{s}^{\circ}$ on the resulting $\tau_{a}$, a perturbation model is applied to demonstrate the sensitivity of $\tau_{a}$ to $\Delta \sigma_{s}^{\circ}$. The sensitivity of $\tau_{a}$ to perturbation $1+\epsilon$ is given as

$$
\tau_{a}\left(\Delta \sigma_{s}^{\circ} \cdot(1+\epsilon)\right)=\frac{\cos \theta}{2} \ln \frac{\Delta \sigma_{s}^{\circ} \cdot(1+\epsilon)}{\Delta \sigma^{\circ}}
$$

which can be rewritten as

$$
\tau_{a}\left(\Delta \sigma_{s}^{\circ} \cdot(1+\epsilon)\right)=\frac{\cos \theta}{2} \ln \frac{\Delta \sigma_{s}^{\circ}}{\Delta \sigma^{\circ}}+\frac{\cos \theta}{2} \ln (1+\epsilon) .
$$

The change in $\tau_{a}$ as a function of the perturbation $\epsilon$ can be defined as

$$
\begin{aligned}
\delta \tau_{a} & =\tau_{a}\left(\Delta \sigma_{s}^{\circ} \cdot(1+\epsilon)\right)-\tau_{a}\left(\Delta \sigma_{s}^{\circ}\right) \\
& =\frac{\cos \theta}{2} \ln (1+\epsilon) \\
& =\frac{\cos \theta}{2} \ln \left(1+\frac{\delta \Delta \sigma_{s}^{\circ}}{\Delta \sigma_{s}^{\circ}}\right) .
\end{aligned}
$$

In order to look at a valid range of $\Delta \sigma_{s}^{\circ}$, the maximum bare soil backscatter values are set based on [44]-[46]. In these studies, backscatter was measured either with a fieldscale radar or spaceborne SAR. Observations at $5.25 \mathrm{GHz}$ at $\mathrm{VV}$ and $\mathrm{HH}$ polarizations over bare soils with different roughness and soil moisture values were used. The findings of these studies are summarized in Table II. Based on these results, the minimum and maximum $\Delta \sigma_{s}^{\circ}$ were estimated to $0.05 \mathrm{~m}^{2} \mathrm{~m}^{-2}$ and $0.7 \mathrm{~m}^{2} \mathrm{~m}^{-2}$, respectively.

\section{Metrics Used for Assessing $\tau_{a}$ and $\Theta_{a}$}

The Spearman Rank correlation coefficient $(\mathrm{R})$ is calculated between the climatologies of $\tau_{a}$ and $\tau_{p}$. Spearman rank correlation is based on a relative ranking of the data, not on absolute values, and does not make any assumption on the nature of the relationship between the different data sets.

To assess the effect of the TU-Wien vegetation correction on the soil moisture retrieval both the normalized backscatter $\sigma^{\circ}(40)$ [see (2), right-hand term] and the surface soil moisture $\Theta_{a}$ [see (2), left-hand term] were correlated with $\Theta_{\text {ERA. The }}$ $\sigma^{\circ}(40)$ is not yet corrected for vegetation, whereas the $\Theta_{a}$ is.
With this analysis, the impact of the vegetation correction on the quality of $\Theta_{a}$ can be identified. However, with this analysis, we only investigate how the vegetation correction improves the temporal dynamics of the soil moisture retrieval. How the vegetation correction impacts the absolute values of soil moisture is not investigated with this approach, although it is expected to be significant.

To test the impact of the existing fixed year-to-year vegetation correction, the dry reference, which incorporates the existing vegetation correction, was substituted by the $\tau_{p}$ to produce a soil moisture product with an interannually varying vegetation correction $\left(\Theta_{\tau_{p}}\right)$, i.e.,

$$
\Theta_{\tau_{p}}(t)=\frac{\sigma^{\circ}(40, t)-\sigma_{\mathrm{dry}}^{\circ}\left(t, \tau_{p}\right)}{\sigma_{\mathrm{wet}}^{\circ}(t)-\sigma_{\mathrm{dry}}^{\circ}\left(t, \tau_{p}\right)}
$$

where $\sigma_{\text {dry }}^{\circ}\left(t, \tau_{p}\right)$ is the new dry reference based on $\tau_{p}$ from AMSR-E scaled to the dry reference (in decibels) with a mean standard deviation scaling as follows:

$$
\begin{aligned}
\sigma_{\mathrm{dry}}^{\circ}\left(t, \tau_{p}\right)=\frac{\tau_{p}(t)-E\left[\tau_{p}(t)\right]}{\mathrm{Sd}\left[\tau_{p}(t)\right]} \mathrm{Sd}[ & \left.\sigma_{\mathrm{dry}}^{\circ}(\mathrm{DoY})\right] \\
& +E\left[\sigma_{\mathrm{dry}}^{\circ}(\mathrm{DoY})\right]
\end{aligned}
$$

where $E$ and $\mathrm{Sd}$ are the mean and standard deviation. The mean and standard deviation scaling is purely to scale the $\tau_{p}$ values to the dry reference values which are in decibels. The whole time series of $\tau_{p}$ is used to calculate the respective mean and standard deviation. The goal of this is to introduce interannual variability in the vegetation correction and subsequently in the soil moisture retrieval. As a consequence, the results only provide information on the differences in the temporal behavior of soil moisture and not absolute values. Because of the scaling of $\tau_{p}$ to the mean and standard deviation of the dry reference, absolute values of soil moisture are not expected to change dramatically.

\section{Results And Discussion}

\section{A. Effect of Bare Soil Backscatter on $\tau_{a}$ Retrievals}

Only a limited number of gridpoints satisfied the conditions of Hansen tree cover less than $10 \%$ and $\tau_{p}$ less than 0.20 . For all land surface areas, $17.8 \%$ of the gridpoints are classified as bare soils, of which only $5.4 \%$ are in climate classes, which are not deserts. This fraction of bare soils was found in the Great Plains and Canadian prairies. The low fraction of bare soils in nondeserts resulted in two different methods to estimate $\Delta \sigma_{s}^{\circ}$; one for deserts and one for all other areas, here referred to as nondesert areas. For every gridpoint in the deserts, it is assumed that the lowest measurements are not affected by vegetation. Hence, the lowest backscatter measurements are taken as $\sigma_{s, \mathrm{dry}}^{\circ}$. For deserts, the $\sigma_{s, \mathrm{dry}}^{\circ}$ varies per gridpoint based on ASCAT observations. For all nondesert areas, results are averaged to one value to obtain a representative value of $\sigma_{s, \mathrm{dry}}^{\circ}$. The variability in $\sigma_{s, \mathrm{dry}}^{\circ}$ is clearly represented in the standard deviation per climate class (see Table III). For climate classes $\mathrm{A}, \mathrm{BS}, \mathrm{C}$, and $\mathrm{D}$, the standard deviation ranges from 1.67 to $2.70 \mathrm{~dB}$, whereas the standard deviation in climate class BW is as high as $4.6 \mathrm{~dB} . \sigma_{s, \mathrm{dry}}^{\circ}$ ranges from -27.01 to $-3.71 \mathrm{~dB}$ for temperate climates (class C) and from -21.91 to $-8.59 \mathrm{~dB}$ for cold climates (class D). For deserts $\sigma_{\mathrm{dry}}^{\circ}$ is highly variable, with values ranging from -37.78 to $-5.89 \mathrm{~dB}$. The variability 
TABLE III

BARE SOIL BACKSCATTER AND $\Delta \sigma_{s}^{\circ}$ FROM DATA AND MODELING

\begin{tabular}{|c|c|c|c|c|c|c|c|c|}
\hline \multirow{2}{*}{ Source } & \multirow{2}{*}{ KGC } & \multicolumn{3}{|c|}{$\sigma_{d r y}^{\circ}[\mathrm{dB}]$} & \multicolumn{3}{|c|}{$\Delta \sigma_{s}^{\circ}[\mathrm{dB}]$} & \multirow{2}{*}{$\Delta \sigma_{s}^{\circ}\left[\mathrm{m}^{2} \mathrm{~m}^{-2}\right]$} \\
\hline & & $\min$ & $\max$ & mean & $\min$ & $\max$ & mean & \\
\hline \multirow{6}{*}{ ASCAT data } & A & -18.29 & -6.14 & -12.29 & & & & 0.31 \\
\hline & BS & -26.49 & -8.35 & -16.25 & & & & 0.13 \\
\hline & BW & -37.78 & -5.89 & -16.93 & & & & 0.10 \\
\hline & $\mathrm{C}$ & -27.01 & -3.71 & -13.15 & & & & 0.26 \\
\hline & $\mathrm{D}$ & -21.91 & -8.59 & -16.79 & & & & 0.11 \\
\hline & average & -27.01 & -3.71 & -15.23 & & & & 0.16 \\
\hline \multirow{2}{*}{ Source } & \multirow{2}{*}{$s[\mathrm{~cm}]$} & \multicolumn{3}{|c|}{$\sigma_{d r y}^{\circ}[\mathrm{dB}]$} & \multicolumn{3}{|c|}{$\Delta \sigma_{s}^{\circ}[\mathrm{dB}]$} & \multirow{2}{*}{$\left.\Delta \sigma_{s}^{\circ}\left[\mathrm{m}^{2} \mathrm{~m}^{-2}\right)\right]$} \\
\hline & & $\min$ & $\max$ & mean & $\min$ & $\max$ & mean & \\
\hline \multirow{6}{*}{ IEM } & 0.5 & -23.01 & -19.74 & -21.74 & -8.52 & -6.11 & -7.71 & 0.03 \\
\hline & 1.0 & -16.40 & -13.51 & -15.27 & -7.30 & -5.09 & -6.54 & 0.10 \\
\hline & 1.5 & -12.64 & -9.90 & -11.55 & -6.77 & -4.67 & -6.06 & 0.21 \\
\hline & 2.0 & -10.57 & -7.88 & -9.50 & -6.54 & -4.46 & -5.82 & 0.32 \\
\hline & 2.5 & -9.80 & -7.16 & -8.76 & -6.43 & -4.34 & -5.69 & 0.36 \\
\hline & average & -23.01 & -7.17 & -13.37 & -8.52 & -4.34 & -6.37 & 0.15 \\
\hline
\end{tabular}
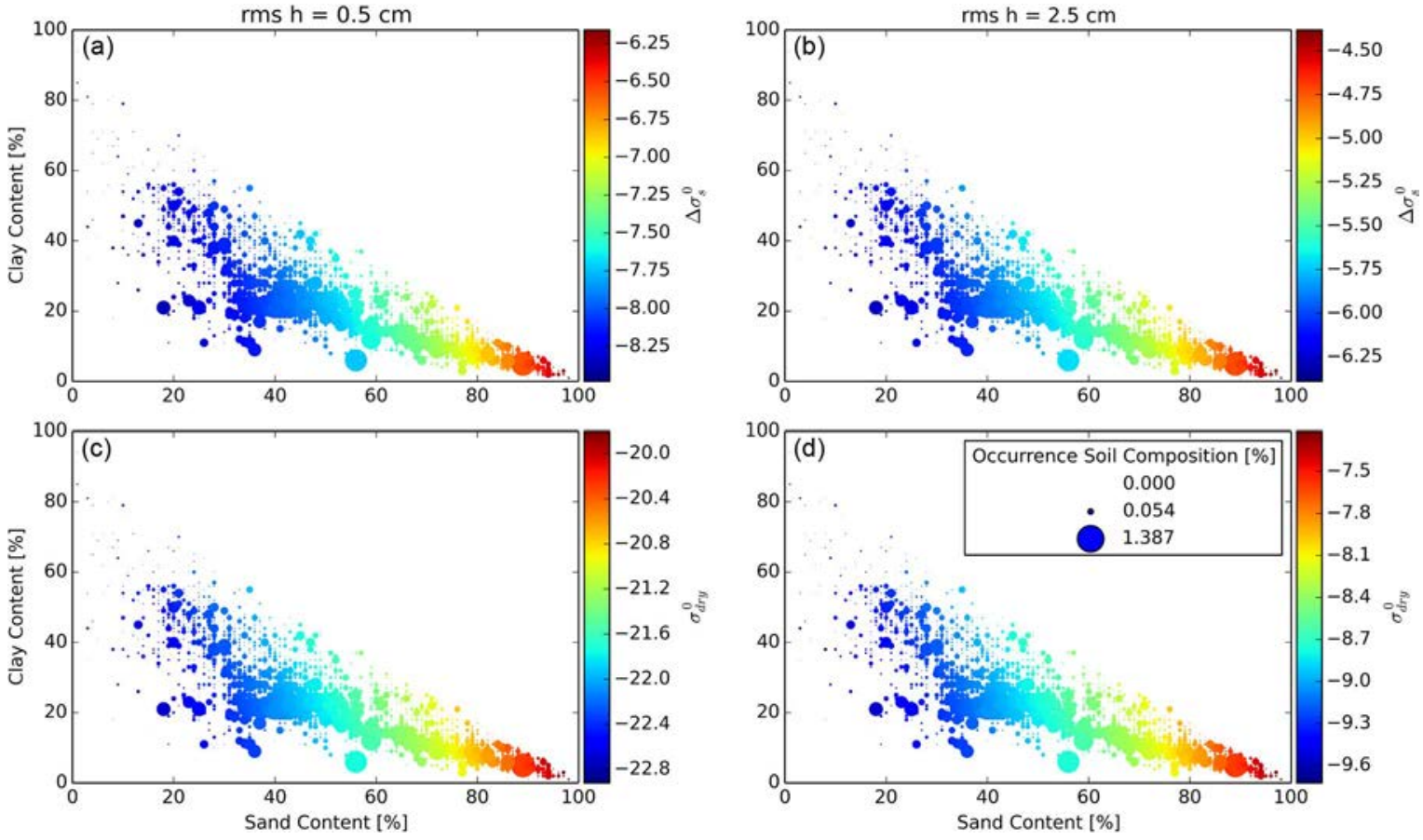

Fig. 4. (a) and (b) Top two graphs show $\Delta \sigma_{s}^{\circ}$ in $\mathrm{dB}$ calculated using IEM and (c) and (d) lower two graphs show the $\sigma_{\text {dry }}^{\circ}$, where $\sigma_{\text {dry }}^{\circ}$ and $\Delta \sigma_{s}^{\circ}$ are calculated using the IEM for smooth (a and c) and rough (b and d) soil surfaces given by two rms heights: $s=0.5 \mathrm{~cm}$ and $s=2.5 \mathrm{~cm}$. Data are displayed according to the global occurrence of soil properties: sand content (depicted on the $x$-axis) and clay content (depicted on the $y$-axis) by the size of the circles. The colorbar depicts the $\sigma_{\mathrm{dry}}^{\circ}$ and $\Delta \sigma_{s}^{\circ}$ with low values in blue and high values in red.

is much higher than for nondesert areas, confirming the importance of a variable $\sigma_{s, \text { dry }}^{\circ}$. Averaging all results from gridpoints located within climate classes A, BS, C, D, and E yields an average $\sigma_{s, \mathrm{dry}}^{\circ}$ of $-15.23 \mathrm{~dB}$. Based on the literature review (see Table II) the $\Delta \sigma_{s}^{\circ}$ is set to a single value of $8 \mathrm{~dB}$. Inserting the average $\sigma_{s, \text { dry }}^{\circ}$ for nondesert areas and the estimate of $\Delta \sigma_{s}^{\circ}$ into (12) leads to a $\Delta \sigma_{s}^{\circ}$ of $0.16 \mathrm{~m}^{2} \mathrm{~m}^{-2}$ for nondesert areas. This value is similar to the value found for relative smooth soils from the literature review, e.g., $1.1>s>0.2 \mathrm{~cm}$ (see Table II).

Fig. 4 shows the results from the IEM modeling for $\sigma_{s, \mathrm{dry}}^{\circ}$ and $\Delta \sigma_{s}^{\circ}$ for using a $s$ of 1 and $2.5 \mathrm{~cm}$. Results are shown according to the respective occurrence of combinations of sand and clay content as derived from the FAO soil map. We have chosen to calculate a weighted average based on occurring soil textures, in order to obtain more representative values for $\sigma_{s, \mathrm{dry}}^{\circ}$ and $\Delta \sigma_{s}^{\circ}$. Results are summarized for all values of $s$ in Table III. Comparing the values obtained from ASCAT observations and the literature study to modeled results of the analyses using IEM confirms that the obtained value of $0.16 \mathrm{~m}^{2} \mathrm{~m}^{-2}$ is characteristic for relatively smooth soils. Modeling yields $\sigma_{s, \mathrm{dry}}^{\circ}$ values ranging from $-23.01 \mathrm{~dB}$ for smooth soils with a $s=1 \mathrm{~cm}$ [see Fig. 4(c)], to $-7.17 \mathrm{~dB}$ for rough soils with a $s=$ $2.5 \mathrm{~cm}$ [see Fig. 4(d)]. The values for $\Delta \sigma_{s}^{\circ}$ were found to range from $-8.54 \mathrm{~dB}$ for smooth soils [see Fig. 4 (a)] to $-4.38 \mathrm{~dB}$ 


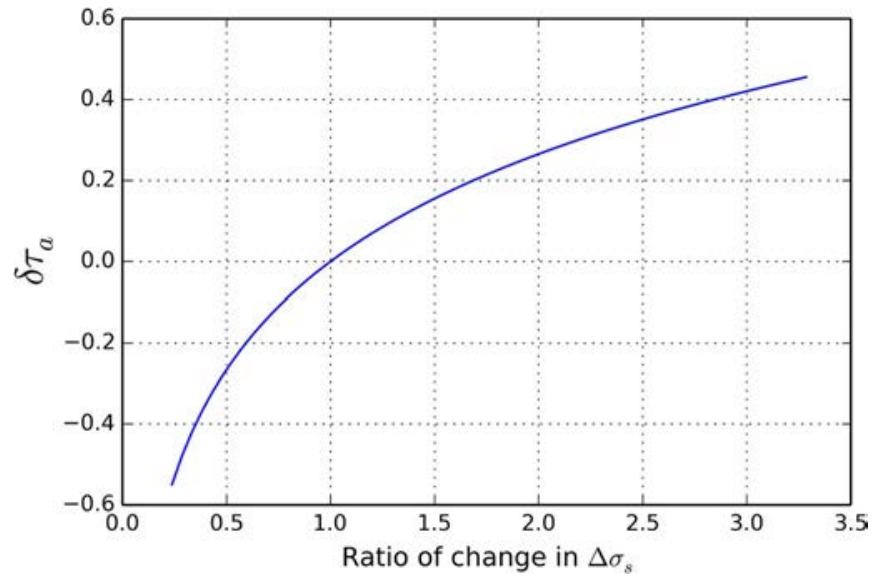

Fig. 5. Sensitivity of $\tau_{a}$ to a change in surface scattering $\Delta \sigma_{s}$ as given by (14), with the ratio of change on the $x$-axis.

for rough soils [see Fig. 4(b)]. The modeling yields smaller values for $\Delta \sigma_{s}^{\circ}$ than the literature study. This can be explained by the fact that most studies assessed in the literature review use backscatter observed under an incidence angle lower than the $40^{\circ}$ angle of ASCAT. The sensitivity of backscatter to soil moisture decreases with increasing incidence angles [44], [45], [47], explaining the lower $\Delta \sigma_{s}^{\circ}$ from the modeling at $40^{\circ} . \Delta \sigma_{s}^{\circ}$ of $8 \mathrm{~dB}$ is on the high end of results from the IEM modeling, i.e., $\Delta \sigma_{s}^{\circ}$ around $8 \mathrm{~dB}$ are only found for $s=0.5 \mathrm{~cm}$.

Based on the modeling study, we can conclude that the estimated values for $\sigma_{s \text {,dry }}^{\circ}$ and $\Delta \sigma_{s}^{\circ}$, based on observations and a literature review, is associated to smooth soils with $s \simeq 1 \mathrm{~cm}$. Assuming that land use over tropical, temperate, and cold climates is mainly either agriculture, tundra, or forest, average microscale random roughness conditions for these surfaces are likely higher than $s=1 \mathrm{~cm}$. Subsequently, $\sigma_{s \text {, dry }}^{\circ}$ in decibels and $\Delta \sigma_{s}^{\circ}$ in $\mathrm{m}^{2} \mathrm{~m}^{-2}$ are likely higher than calculated from ASCAT observations over the bare soil areas in the Canadian Prairies and Great Plains. In [48] and [49], it is stated that 1.5 and $1.6 \mathrm{~cm}$ are most representative for typically observed normal conditions of roughness. Considering the results from the data analysis, the literature review and the modeling, the $\Delta \sigma_{s}^{\circ}$ in $\mathrm{m}^{2} \mathrm{~m}^{-2}$ for nondeserts calculated from observations was adjusted. For the ultimate calculation of $\tau_{a}, \Delta \sigma_{s}^{\circ}$ is set to the modeled value for $s=1.5 \mathrm{~cm}: 0.21 \mathrm{~m}^{2} \mathrm{~m}^{-2}$. For deserts, $\Delta \sigma_{s}^{\circ}$ is lowered to the weighted average of the IEM analyses: $-6.37 \mathrm{~dB}$. This leads to the following values being used for $\Delta \sigma_{s}^{\circ}$ :

$$
\Delta \sigma_{s}^{\circ}= \begin{cases}0.21\left[\mathrm{~m}^{2} \mathrm{~m}^{-2}\right], & \text { for } \mathrm{KGC}=A|B S| C|D| E \\ \left(10^{\frac{6.37[\mathrm{~dB}]}{10}}-1\right) & \\ \cdot \sigma_{s, \mathrm{dry}}^{\circ}(x, y)\left[\mathrm{m}^{2} \mathrm{~m}^{-2}\right], & \text { for } \mathrm{KGC}=\mathrm{BW}\end{cases}
$$

where for climate class $\mathrm{BW}, \sigma_{s, \mathrm{dry}}^{\circ}$, converted from $\mathrm{dB}$ in $\mathrm{m}^{2}$ $\mathrm{m}^{-2}$, varies spatially for every gridpoint, which is denoted with the suffix $(x, y)$.

When calculating $\tau_{a}$, the bare soil backscatter $\Delta \sigma_{s}^{\circ}$ is assumed static for all areas apart from deserts. This very likely introduces spatial biases in $\tau_{a}$ because the range of surface roughness conditions changes from pixel to pixel and is not accounted for. The sensitivity analyses assesses the effect of $\Delta \sigma_{s}^{\circ}$ on $\tau_{a}$. Fig. 5 shows for decreasing $\Delta \sigma_{s}^{\circ}$ from the estimated average value of 0.21 to 0.05 will lead to a decrease in $\tau_{a}$ of 0.55 , whereas increasing $\Delta \sigma_{s}^{\circ}$ to 0.7 will increase $\tau_{a}$ with 0.46 . However, it needs to be taken into account that the sensitivity analysis is performed using extreme values. Smooth soils or ploughed soils as prepared for the experiments described in Section III-B are rare and unrealistic to span the entire extent of a pixel. Taking into account the natural conditions of the soils, a pixel of ASCAT will not solely contain recently ploughed soils or only smooth soils but is a mix of different states of soil surface roughness. Furthermore, one needs to keep in mind that how soil surface roughness affects satellite scale observations is not yet well understood. Fieldscale surface roughness as measured during experiments, parameterized by two variables, is not assumed representative for the effective surface roughness at the satellite scale [50]. Taking this into account, one can assume that soil surface roughness is unlikely to reach extreme values of, e.g., 0.05 or $4 \mathrm{~cm}$ over a whole pixel of ASCAT. A decrease in $\Delta \sigma_{s}^{\circ}$ happens in relatively smooth soils (see Fig. 4 and [44]), e.g., soils with a lower microscale roughness, which are expected to be in natural areas such as deserts, savanna, and rangeland. However, for most of these areas, which fall in climate class $\mathrm{B}, \Delta \sigma_{s}^{\circ}$ is estimated at every gridpoint from the ASCAT data. The analysis demonstrates that for areas where $\tau_{a}$ gives lower values compared with $\tau_{p}$, the estimated $\Delta \sigma_{s}^{\circ}$ might be too low. Considering that $\Delta \sigma_{s}^{\circ}$ of $0.21 \mathrm{~m}^{2} \mathrm{~m}^{-2}$ is found in relatively smooth soils, i.e., $s=1.5 \mathrm{~cm}$, this estimate could be too low for soils with a higher surface roughness. Although the estimation of $\Delta \sigma_{s}^{\circ}$ clearly introduces a bias, the spatial distribution and temporal variability of $\tau_{a}$ still gives valuable information on how the TU-Wien model describes the vegetation and makes it comparable to $\tau$ values derived from other sensors. In the following, the results are discussed in general and per climate class.

\section{B. Comparing $\tau_{a}$ and $\tau_{p}$}

Figs. 6 and 7 show the global maps and boxplots per KGC of both $\tau_{a}$ and $\tau_{p}$ average values over the period 2007 to 2011 . When looking at the spatial distribution of the mean values of $\tau_{a}$ and $\tau_{p}$, spatial patterns are similar, particularly over tropical forests, southern Europe and North America. As the boxplots show (see Fig. 7), for both products, $\tau$ values decrease from values close to 1.0 for climate class Af to values between 0.4 and 0.6 for climate classes Am and As to values close to 0 for climate classes BWh and BWk. Higher values are found in climate class $\mathrm{C}$, with lowest values in classes that are characterized by a hot summer, identified by the suffix "a" in the climate class classification, indicating drier conditions and a lower vegetation density. In cold climates particularly areas with dry winters (Dw) show very similar patterns with increasing values for both $\tau_{a}$ and $\tau_{p}$ with decreasing summer temperatures. The clear spatial patterns in $\tau_{a}$ demonstrate that the assumption of a spatially constant $\Delta \sigma_{s}^{\circ}$ for nondesert areas is reasonable to obtain a fist estimate of $\tau_{a}$. In general, values for $\tau_{a}$ are 0.15 lower than values found for $\tau_{p}$. A potential explanation for this is that $\Delta \sigma_{s}^{\circ}$ is estimated too low. $\Delta \sigma_{s}^{\circ}$ could be too low due to the relatively large correlation length that has been used in the IEM modeling. Lowering the correlation length to the average value found by [49] would increase $\tau_{a}$ by 0.08 , bringing 

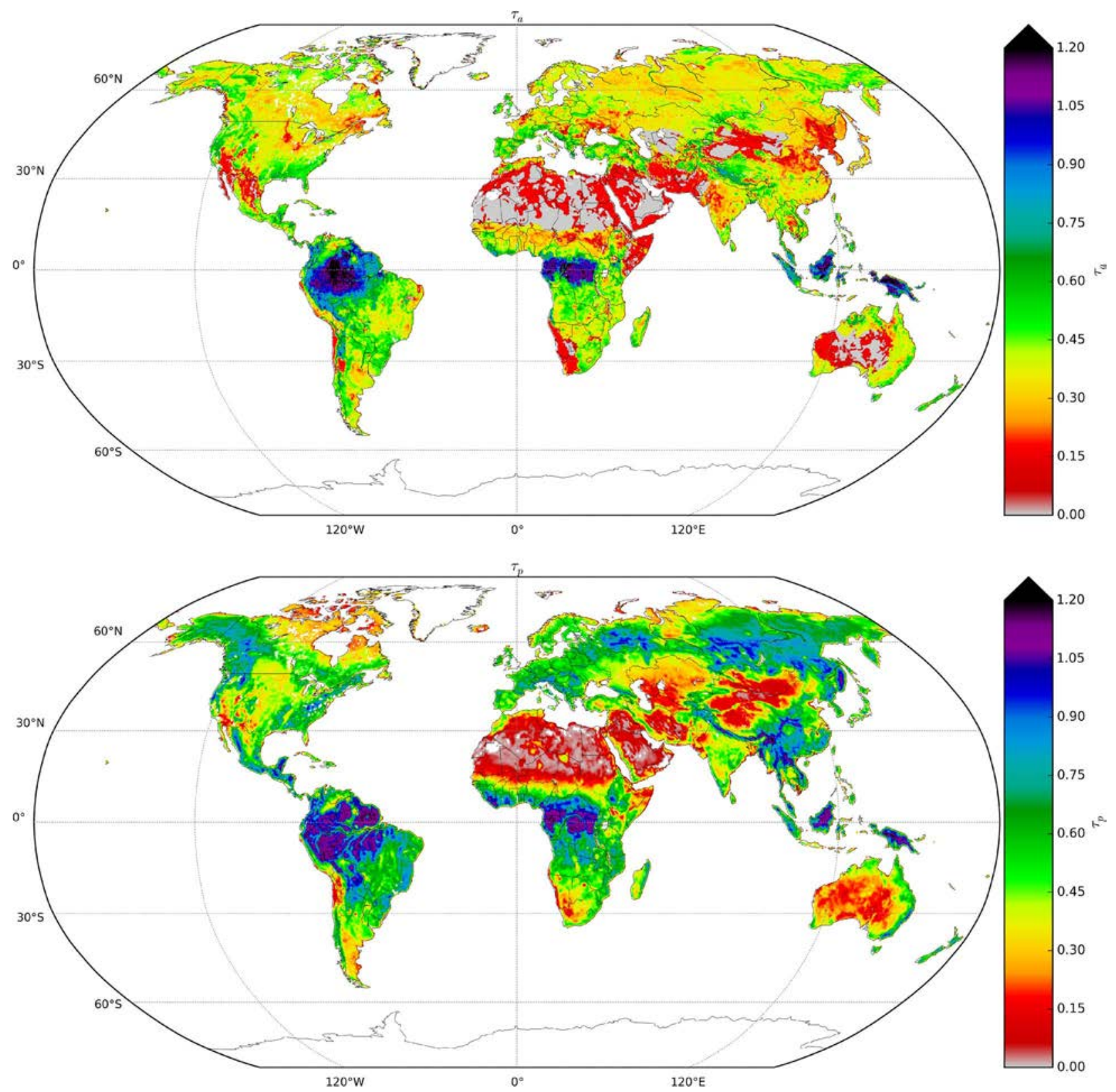

Fig. 6. Global map of mean (a) $\tau_{a}$ and (b) $\tau_{p}$ calculated over the period from 2007 to 2011.

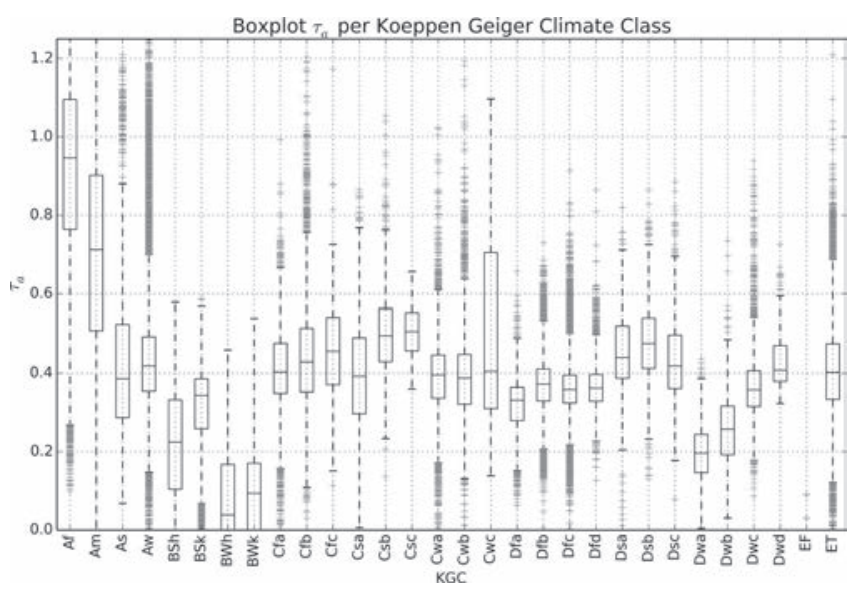

(a)

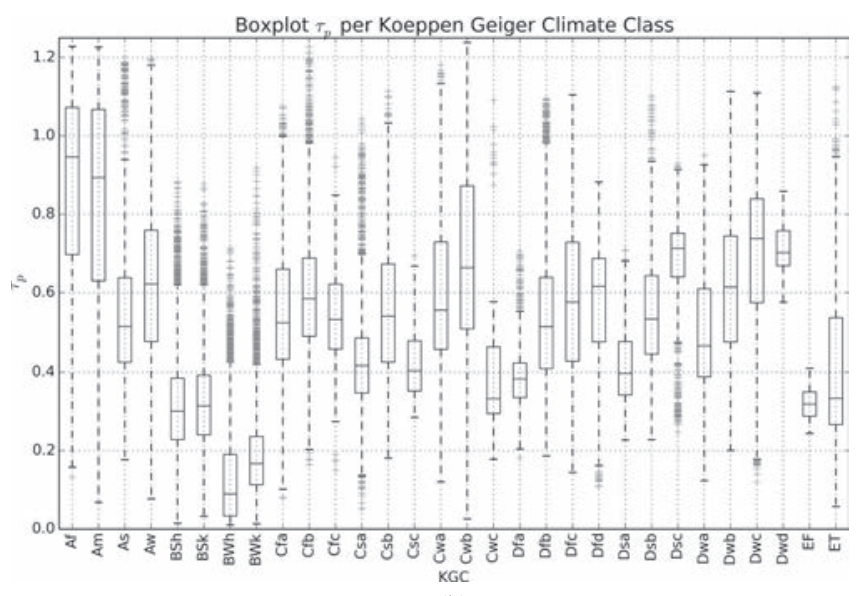

(b)

Fig. 7. Boxplots of (a) $\tau_{a}$ and (b) $\tau_{p}$ per KGC. 


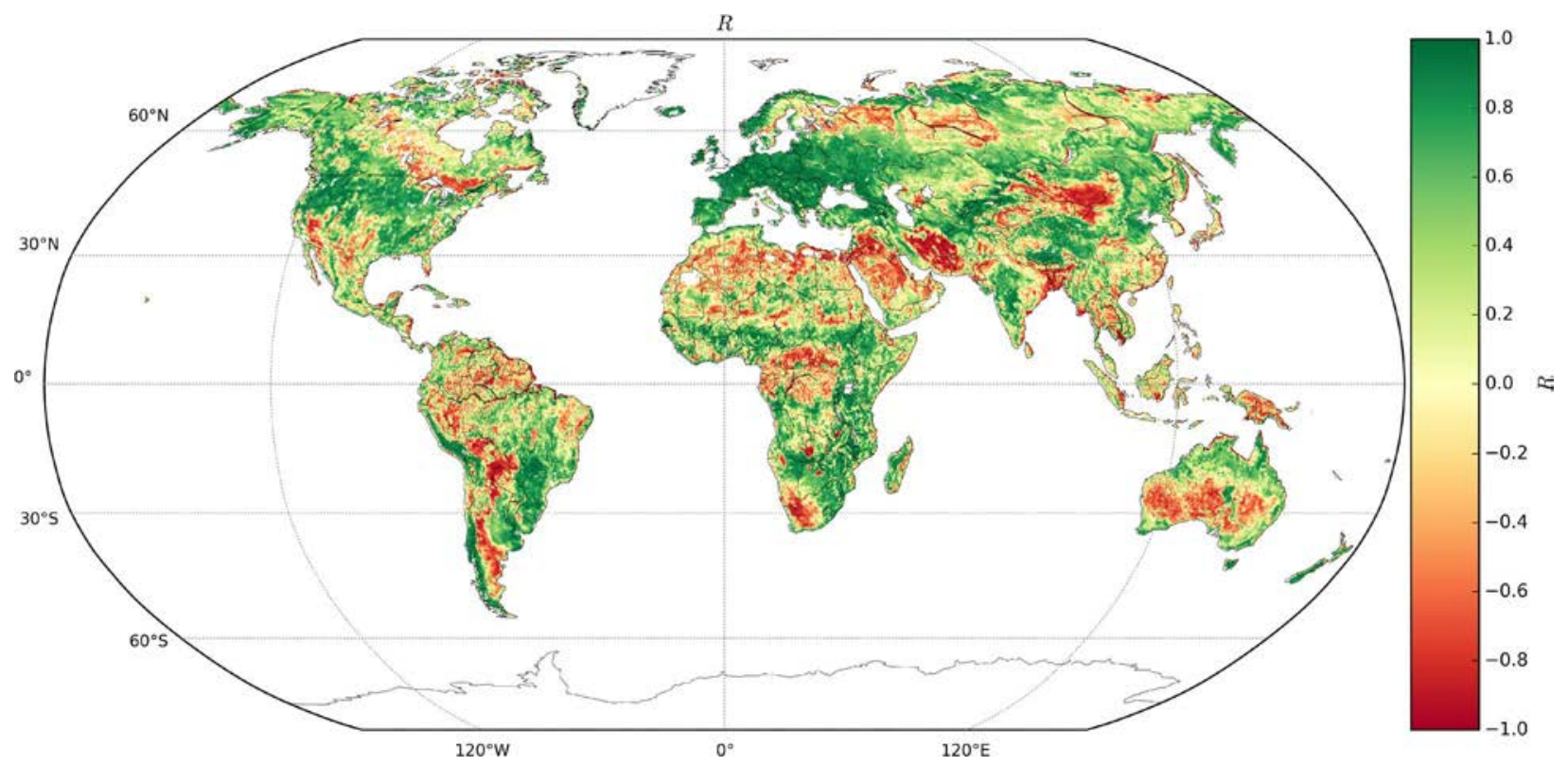

Fig. 8. Global Spearman rank correlation coefficients between $\tau_{a}$ and $\tau_{p}$.

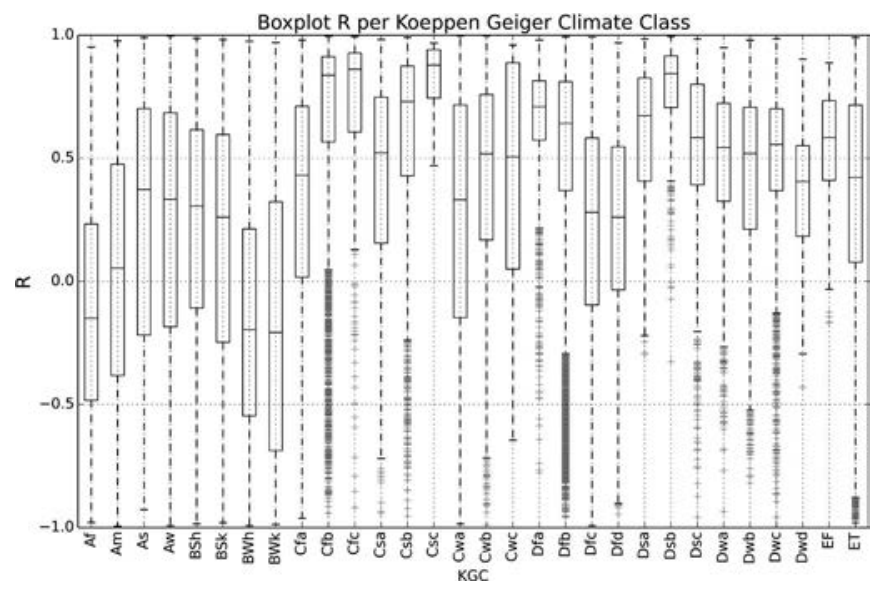

Fig. 9. Boxplot of the Spearman correlation coefficients per $\mathrm{KGC}$ for $\tau_{a}$ and $\tau_{p}$.

it closer to the values found for $\tau_{p}$. On top of this, $\tau_{a}$ shows particularly lower values in cold climates, i.e., northern Europe, Russia, and North America. The comparison of absolute values of $\tau_{a}$ and $\tau_{p}$ are discussed in detail in the following.

Fig. 8 shows the results of the Spearman correlation coefficient between the climatologies of $\tau_{a}$ and $\tau_{p}$. The boxplots (see Fig. 9) show the distribution of the correlation per KGC. High correlation coefficients are observed over temperate and cold climates (climate classes $\mathrm{C}$ and $\mathrm{D}$ ). In deserts and drylands (climate class BWh and BWk), clearly negative correlations are observed. Fig. 10 shows the climatologies of $\tau_{a}$ and $\tau_{p}$ for nine gridpoints with different land cover and in different climate classes (see Fig. 3 for locations). Intra-annual variability is in general low for $\tau_{a}$ (around 0.1) and for most gridpoints lower than for $\tau_{p}$.

1) Equatorial Regions (KGC: A): In tropical climates, both $\tau_{a}$ and $\tau_{p}$ show distinctively high values (see Fig. 6), i.e., climate class A, can be easily distinguished with the median values from 0.44 to 0.99 (see Fig. 7). Average values for climate class Af, Rainforests, respectively, agree very well with each other. However, values for $\tau_{p}$ are on average 0.17 higher in monsoon areas (Am) and savannas (As) than $\tau_{a}$, which is close to the overall bias found between $\tau_{a}$ and $\tau_{p}$. The temporal comparison between $\tau_{p}$ and $\tau_{a}$ in tropical climates shows both weak negative and weak positive correlations. The cause for these mixed weak correlations is the small intra-annual variability for both $\tau_{a}$ and $\tau_{p}$ [see Fig. 10(a)]. The same conclusion was drawn by [18] who found a low intra-annual variability in $\tau_{p}$. It needs to be considered that the Spearman correlation coefficient is not the appropriate metric in regions with low variation of the signal. A more suited metric is the mse (see Fig. 11), as calculated in [2], which is a function of the correlation coefficient, the standard deviation and the mean of the time series. Looking at the mse between $\tau_{p}$ and $\tau_{a}$ over tropical rainforests and deserts, the mse does not show distinctly higher values than in other regions. Hence, it supports the assumption that the low correlations are caused by the minimal variation in $\tau_{p}$.

Figs. 8 and 11 show negative correlations and high errors in some regions belonging to class Aw (equatorial climate with dry winter), i.e., north of the African tropical rainforest, over Cameroon, Central African Republic, and South Sudan. When looking at the mse (see Fig. 11) it shows that this area is characterized by relatively high mse: mse $>0.10$. The time series plots [see Fig. 10(c)] show little variation in $\tau_{a}$, but the highest value lies around February, whereas $\tau_{p}$ has its minimum at this time, which coincides with the end of the dry season. Only from July to October both $\tau_{a}$ and $\tau_{p}$ increase; the rest of the year, the behavior of the time series is opposite here, where $\tau_{a}$ also does not follow the precipitation regime. The different behavior of $\tau_{a}$ and $\tau_{p}$ is subject to further investigation.

2) Arid Regions (KGC: B): In arid climates, e.g., deserts, climate class $\mathrm{B}, \tau_{a}$ and $\tau_{p}$ show low values, between 0.0 and 0.39 . Values here correspond very well to each other with almost no bias between the two products for climate classes BSh and BSk, i.e., bias $=0.04$. For deserts (climate classes BWh and BWk), the bias between the two products is larger, where $\tau_{a}$ is on 


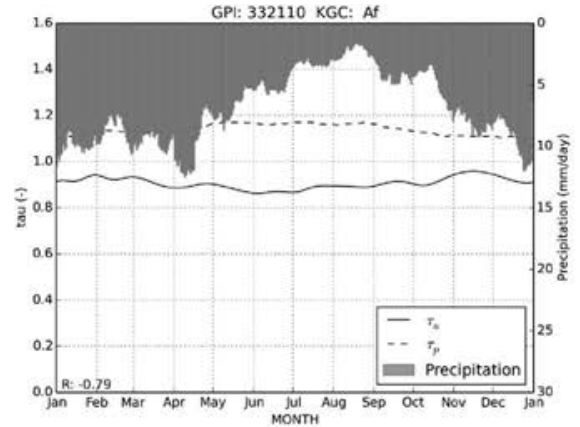

(a)

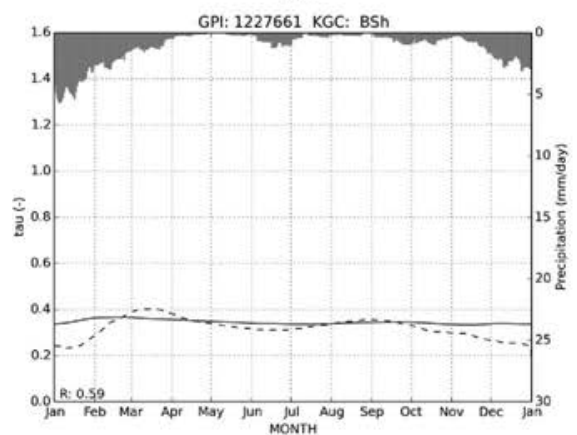

(d)

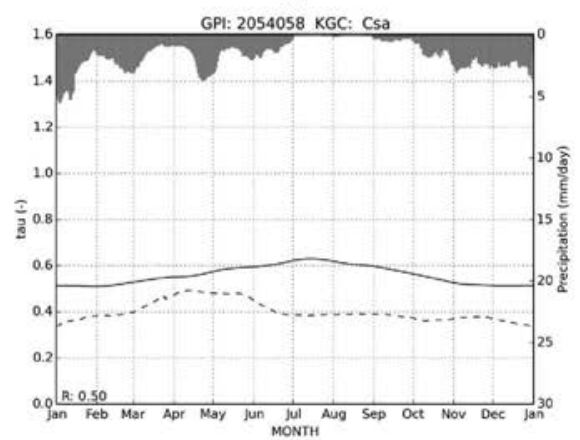

(g)

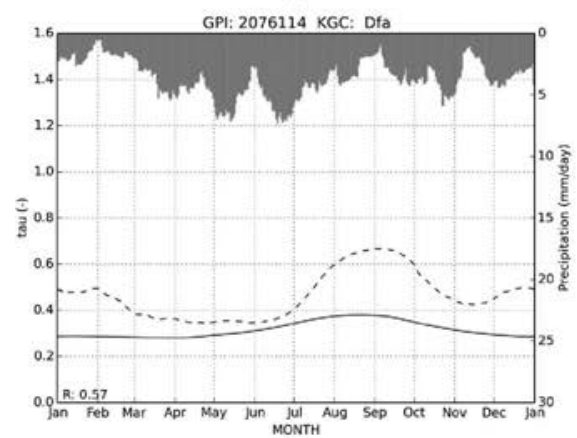

(j)

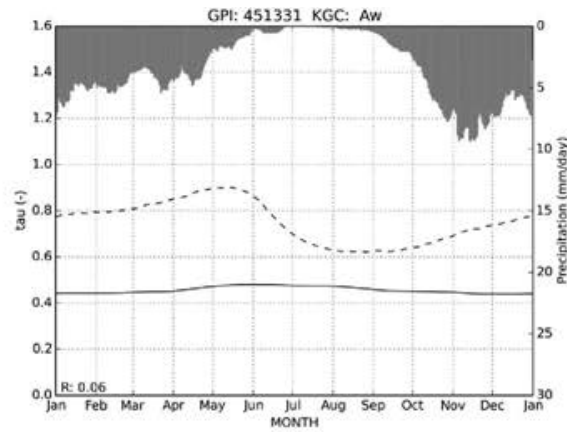

(b)

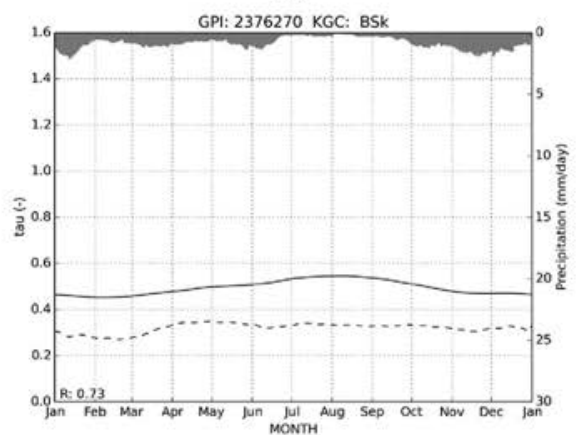

(e)

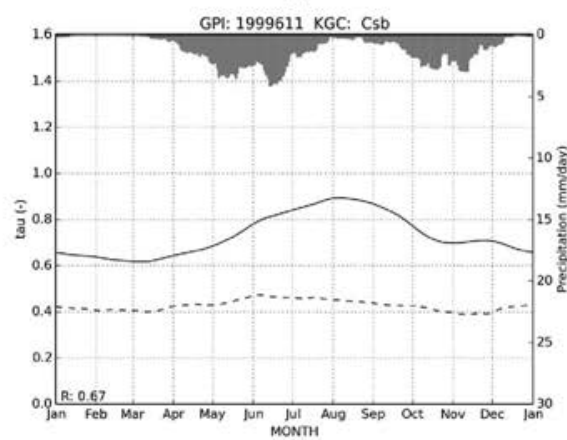

(h)

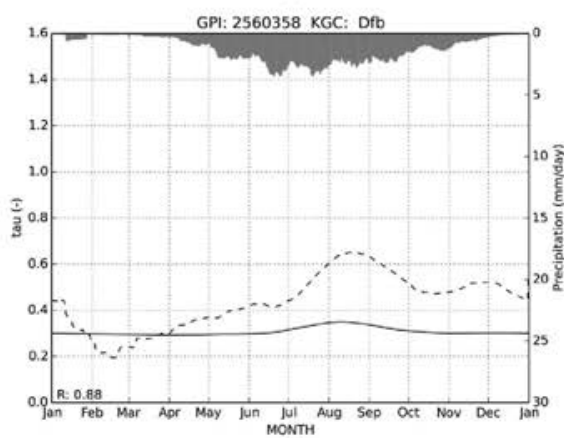

(k)

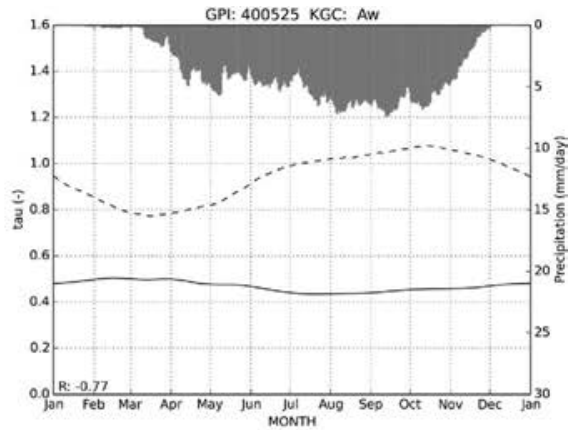

(c)

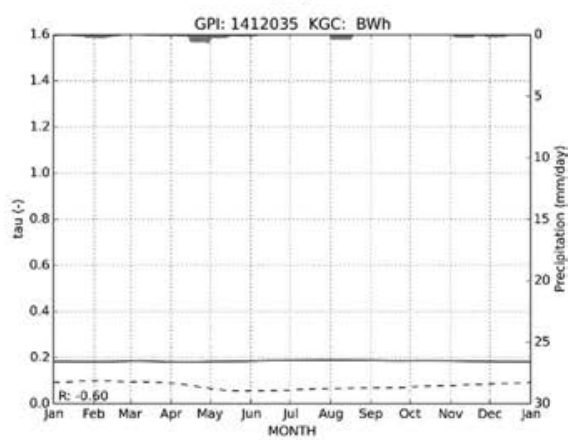

(f)

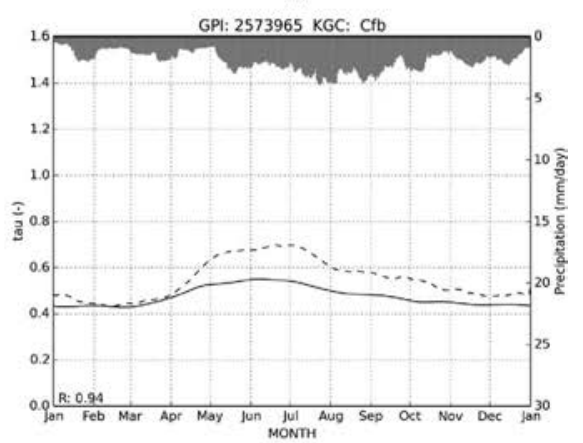

(i)

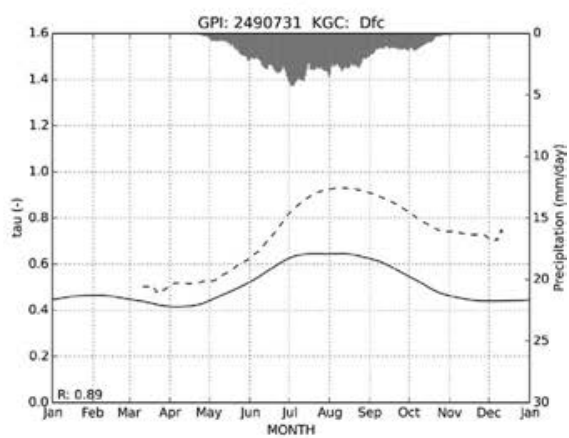

(I)

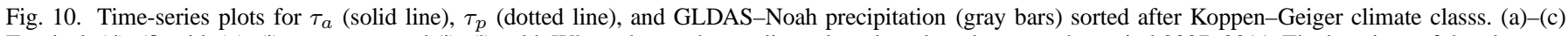

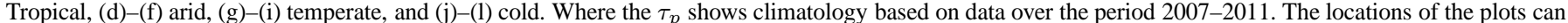
be found in Fig. 3. The numbers above the plots represent the gridpoints and the Koppen-Geiger climate classs and R gives the Spearman correlation coefficient.

average 0.21 lower than $\tau_{p}$. This originates mainly from areas where backscatter is extremely low, e.g., in sand dunes, and $\tau_{a}$ shows values close to 0 or even negative. $\Delta \sigma_{s}^{\circ}$ is extremely low in sand dunes, e.g., $-32 \mathrm{~dB}$, since it is obtained for every gridpoint individually based on ASCAT observations, leading to $\tau_{a}$ values of 0 . Spatial patterns between $\tau_{a}$ and $\tau_{p}$ are very similar in deserts, with higher values in Yemen and in mountainous areas in the Sahara desert. Although the mean values of the two products correspond well to each other, negative correlations are observed between $\tau_{a}$ and $\tau_{p}$. Previous studies have shown that the $\tau_{p}$ shows a good correspondence to both precipitation and NDVI over these regions [17], [18]. Multiple processes can play a role in deserts, introducing discrepancies and low correlations between $\tau_{a}$ and $\tau_{p}$. Most importantly, as for tropical forest, variation in vegetation is very low in most parts of deserts [see Fig. 10(e)]. In fact, many areas do 


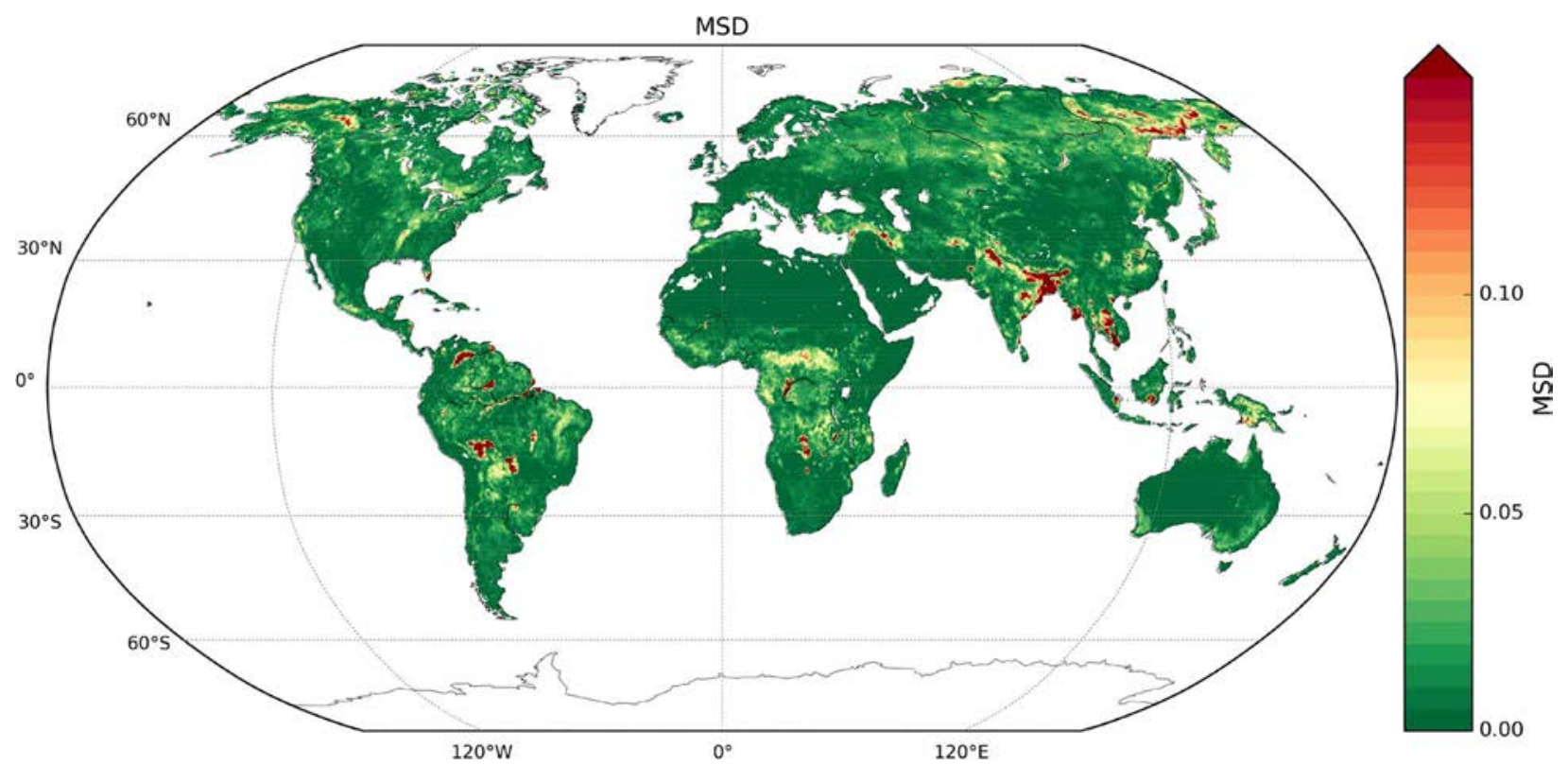

Fig. 11. Global mse between $\tau_{a}$ and $\tau_{p}$.

not have any vegetation at all [see Fig. 10(f)]. Consequently, correlation coefficients between $\tau_{a}$ and $\tau_{p}$ are meaningless for some areas. In these areas, the $\tau_{a}$ and $\tau_{p}$ signal do not correspond to vegetation water content but are sensitive to other surface parameters.

For example, soil volume scattering can play a role in deserts [51], which are caused by dry sand soils. In wet soils, microwaves do not penetrate the soil very deep since the soil moisture forms a dielectric surface; hence, volume scattering does not need to be taken into account. However, studies have demonstrated that, in dry sand soils, the penetration depth of the microwaves can be large, i.e., up to several meters, causing volume scattering [51] and the chance of hitting subsurface bedrock. Since volume scattering is also the prevailing scattering mechanism in vegetation, volume scattering due to dry soils can cause an increase in $\tau_{a}$ when no vegetation is present.

When microwaves do hit subsurface bedrock or rocks, $\tau_{a}$ is also affected. Rocks and bedrock patterns at the same scale as the wavelength of ASCAT can increase the microscale surface roughness of the scattering surface. Since the effect on the slope and curvature of the $\sigma^{\circ}-\theta$ curve is the same for increasing surface roughness as for increasing vegetation density, i.e., the slope of the $\sigma^{\circ}-\theta$ curve decreases with increasing soil surface roughness [45], increasing microscale roughness can increase $\tau_{a}$. Rocky surfaces can be found in desert pavements, pediments, and regolithic slopes. Pavements are flat surfaces, formed by long-term aeolian erosion, with pebbles and cobbles on the (sub)surface. Pediments form at the foot of mountainous areas, and are characterized by eroded bedrock surfaces covered with pebbles. Since weathering in deserts is a mechanical process, and not driven by water, it results in coarse angular rocks with the size of pebbles $(2-6.4 \mathrm{~cm})$ and cobbles $(6.4-25.4 \mathrm{~cm})$ covering many areas in deserts [52], [53]. With a wavelength of $5 \mathrm{~cm}, \mathrm{C}$-Band is highly sensitive to the presence of pebbles and cobbles on the surface or in the subsurface, increasing $\tau_{a}$. In addition, buttes are distinctive landforms in deserts, which consist of steep-sided hills and cliffs [52], which can function as corner reflectors, leading to higher backscatter and potentially increasing $\tau_{a}$. Here, it needs to be considered that surface roughness is difficult to define in microwave remote sensing, and represents the roughness of the boundary between two media with different dielectric properties. If during dry periods volume scattering or scattering from subsurface bedrock is the dominant mechanism, a high $\tau_{a}$ is observed, leading to negative correlations. Furthermore, the signal-to-noise ratio is very low in deserts, which makes a change detection very challenging. In conclusion, not considering the generally low vegetation density and dynamics in deserts, the variation observed in $\tau_{a}$ can be originating from sensor noise, surface roughness changes, volume scattering, a wrong estimation of the wet reference, or some yet unknown physical process, possibly explaining the high values for $\tau_{a}$ and low correlation coefficients with $\tau_{p}$.

3) Warm Temperate Regions (KGC: C): Temperate regions cover parts of Europe, Argentina, Eastern China, and U.S., and are dominated by croplands. In general, $\tau_{a}$ shows lower values for temperate climates than $\tau_{p}$, with an average bias of 0.15 . This bias originates mainly from climate classes $\mathrm{Cwa}$ and $\mathrm{Cwb}$, temperate climates with a dry winter and hot and warm summer. Climate class Cwa covers part of the Himalaya mountains and mountainous regions in China, excluding the Tibetan Plateau, which falls in climate class ET, where retrieval is potentially hampered due to the rough terrain. Analysis of RADARSAT2 observations over the Italian Alps showed a difference in backscatter values of 8-9 dB attributed to extreme topography [54]. Although backscatter is normalized for topography in the TU-Wien retrieval algorithm, extreme topography, as found in the Himalayas, can still cause ambiguity in backscatter observations and thus in $\tau_{a}$. When looking at spatial patterns and mean values of $\tau_{a}$ and $\tau_{p}$, they are similar in Southern Europe and the Southern USA. In Southern Europe, higher values are found for both $\tau_{p}$ and $\tau_{a}$ in Northern Spain, around the Mediterranean and the coastal regions of Turkey. For both products, the inland of Turkey and Iran show lower values than the coastal areas. Moreover, over North America, similar patterns are found, with low values in the southeastern part of U.S. and higher values in the northwestern part. Fig. 7 shows 
that for temperate climates, both products show lower values in regions with hot summers, i.e., Cfa, Csa, and Cwa. Both $\tau_{p}$ and $\tau_{a}$ are increasing with decreasing summer temperatures, demonstrated by the increasing averages from, e.g., Cfa to $\mathrm{Cfc}$.

Correlation coefficients between $\tau_{a}$ and $\tau_{p}$ are very high for temperate climate regions [see Figs. 7, 8, and 10(h)-(1)]. This is demonstrated by the high correlation coefficients of $>0.7$ (see Fig. 9) in KGC classes C. For temperate climates with hot summers, i.e., class $\mathrm{Cfa}$, Csa, and Cwa, the correlation coefficients are lower than for the other temperate classes, which have a median correlation below 0.5 . One explanation for this may be volume scattering, as described in the section on arid regions, taking place in summer when soils are very dry. In particular, in Spain and in the southeast of U.S., this has been observed, where high backscatter values occur in dry periods [55], [56]. In some cases, total backscatter only decreases after the occurrence of a rain event. Due to the rainfall event, the main scattering mechanism shifts from volume scattering to surface scattering, decreasing the $\tau_{a}$.

4) Cold Regions $(K G C: D)$ : In cold climates (climate class D), characterized by tundra, taiga, and forests, $\tau_{a}$ shows lower values compared with $\tau_{p}$, particularly over Canada, Alaska, and Russia. The average bias between $\tau_{a}$ and $\tau_{p}$ is higher here than for all other climate classes, i.e., 0.21. This bias originates mainly from climate class Dfc and Dwc, cold climates with cool summers, and either dry summers or dry winters, and these classes cover mainly boreal forests and taiga. There are different reasons that might explain this phenomenon. First, the estimated sensitivity of bare soil backscatter $\Delta \sigma_{s}^{\circ}$ may be too low, e.g., because increasing vegetation cover increases the soil surface roughness, e.g., by the presence of litter on the surface and roots in the subsurface. However, we do not see these particularly low values, e.g., the median negative bias for climate classes Dfc and Dwc is close to 0.5, for $\tau_{a}$, in other forested areas, which would be the case if the problem would lie with the $\Delta \sigma_{s}^{\circ}$ estimation. Another more likely reason could be a bias in the estimation of the dry reference. Additional analysis revealed that the wet reference $\sigma_{\text {wet }}^{\circ}$ shows very little variation between climate classes $\mathrm{A}, \mathrm{BS}, \mathrm{C}$, and D with an overall mean and standard deviation of 0.47 and 0.96 , respectively. When comparing subclasses with similar $\tau_{p}$ values from climate classes $\mathrm{A}$ and $\mathrm{D}$ the dry reference in climate classes Dfc and Dwc is on average $3 \mathrm{~dB}$ lower than in climate classes As and Am and up to $5 \mathrm{~dB}$ lower than in climate class Af. This suggests that the dry reference might be estimated too low in cold climates where land cover is characterized by boreal forests. Since the wet reference can be considered the same for these classes, a lower dry reference leads to lower $\tau_{a}$ values. Several processes could possibly explain the low estimates for the dry reference. In the TU-Wien retrieval algorithm, the dry reference is estimated based on the lowest observed backscatter values per gridpoint. Since the dielectric constant of ice is significantly lower than that of water [57], frozen soils are characterized by a lower backscatter, which can be similar to backscatter from dry soils [58]. Hence, even if backscatter is obtained during frozen soil conditions, we assume these values are comparable to dry soil surface conditions. A possible explanation for lower dry reference values compared with more temperate climates, may be that in areas with an extended period of freezing, frozen conditions extend to the water content in vegetation [59], and this leads to a decrease in backscatter. This decrease in backscatter due to the freezing of trees has been observed and modeled in other studies using L-Band SAR and C-Band SIR-C observations [60]-[62] over boreal forests. This hypothesis is supported by the extent of the low values for $\tau_{a}$, which only occur in boreal forests and taiga and not in less vegetated regions such as the northern parts of the Siberian Plain.

In cold climates, many other natural processes can cause strong variations in backscatter, i.e., freeze-thaw cycles, snow cover, and ponding water on frozen soils or snow. In springtime, when temperatures are above freezing point, surface water can form from snow melt and thawing of frozen soils. During this time, backscatter values can decrease strongly, due to the presence of ponding water on the surface as shown in [63]. The work in [1] found that artifacts in the soil moisture time series that leads to low correlations between in situ soil moisture and satellite soil moisture are found in northern latitudes. These artifacts are assumed caused by strong backscatter variations due to freeze-thaw cycles or specular reflection on ponding water, which decreases the returned backscatter signal. Snow can also contribute to the backscatter signal, originating from three components, the top of the snow pack, volume scattering from within the snow pack, or the underlying soil. When the snow pack is dry, it is practically transparent, and the backscatter signal is controlled by the underlying soil. However, if the top of the snow pack is wet and smooth, backscatter originates from the top of the snow pack and can be as low as or even lower than from a dry soil. However, when calculating the dry reference, outliers are removed, and this subsequently masks backscatter values obtained during freeze-thawing cycles, ponding water, and wet snow cover. Naturally, the outlier removal is an automated procedure and can be subject to error. However, since the dry reference is an average of many observations, the contribution of these spurious values is assumed small.

The temporal behavior of $\tau_{a}$ and $\tau_{p}$ is very similar to each other, although correlation coefficients are lower than for temperate climates. In particular, in Canada around the Hudson Bay, and the northern parts of Ural and Siberia, negative correlations occur. However, these areas are characterized by the presence of numerous lakes. As discussed earlier, the presence of open water and ponding water can cause artifacts in the retrieved $\tau_{a}$ and $\tau_{p}$. The retrieval of both soil moisture and vegetation optical depth in northern latitudes is hindered by the presence of snow cover, freeze-thaw cycles, and frozen soils and ponding water on the surface. Further research is planned to look at the estimation of the dry reference and the relation between the lowest backscatter values found for every gridpoints and the surface conditions at the time of observation.

5) Wetlands: In wetlands and regularly or permanently flooded regions such as irrigated areas and floodplains, i.e., the Ganges and Mekong floodplain, the Okavango Delta and rice fields in Malaysia $\tau_{a}$ shows negative correlations with $\tau_{p}$ (see Fig. 8) and very high values for mse (see Fig. 11). Previous studies have emphasized that care should be taken with interpreting $\tau_{p}$ observations in areas with large open water areas [17], [31], [64]. For active microwave, backscatter is controlled by the roughness of the water surface. Hence, the backscatter is a function of wind direction and impedes the retrieval of the $\tau_{a}$. Consequently, this can lead to low correlations between both products. 


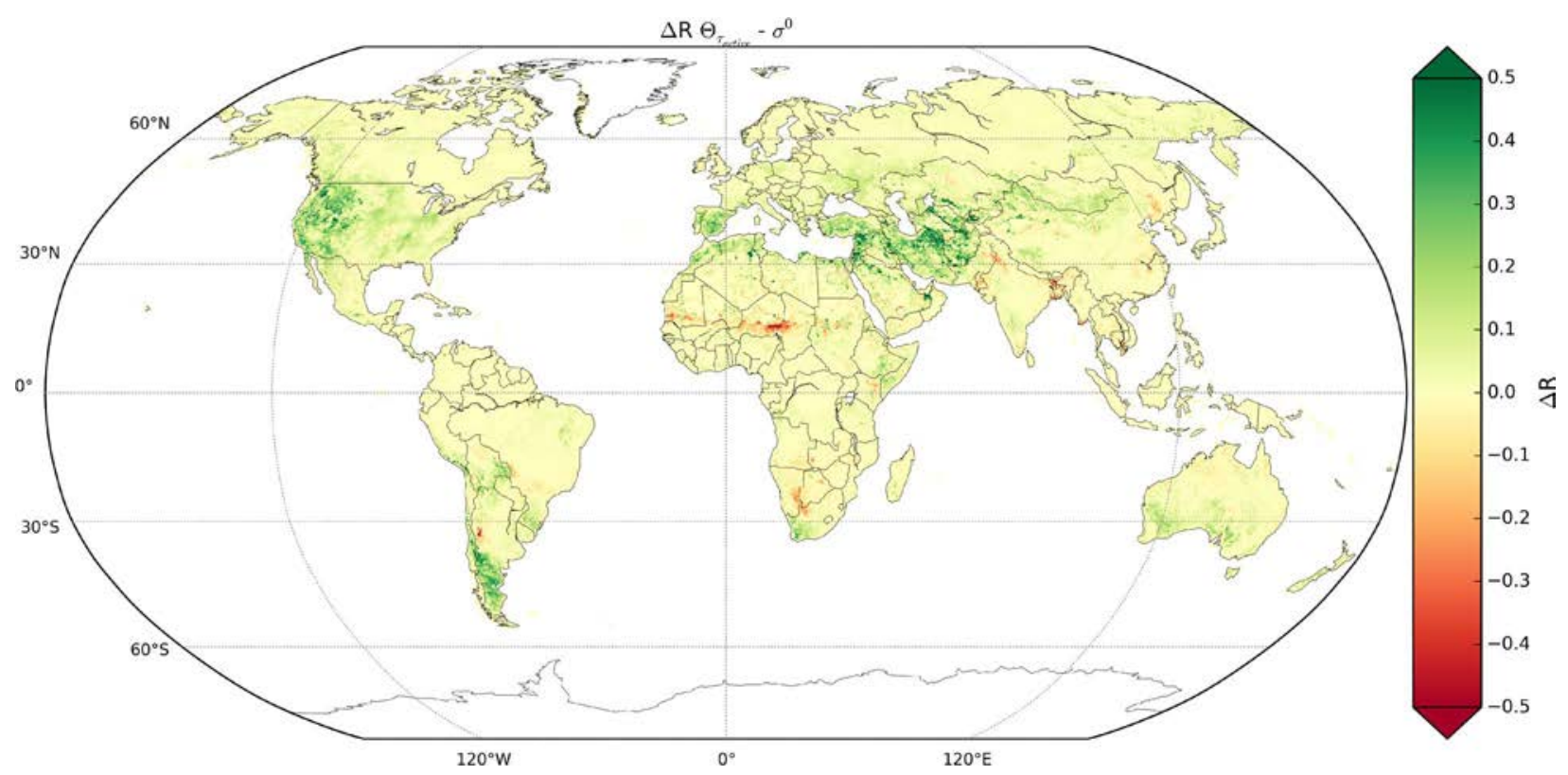

Fig. 12. Difference in Spearman correlation coefficients between $\Theta_{a}$ and $\Theta_{\mathrm{ERA}}$ and $\sigma^{\circ}(40)$ and $\Theta_{\mathrm{ERA}}$, where positive values indicate areas where the correlation between $\Theta_{a}$ and $\Theta_{\mathrm{ERA}}$ is higher than between $\sigma^{\circ}(40)$ and $\Theta_{\mathrm{ERA}}$, i.e., areas with positive impact of the vegetation correction.

\section{Effect of $\tau_{a}$ on Soil Moisture Retrievals}

Since $\tau_{a}$ is a function of both $\Delta \sigma^{\circ}$ and $\Delta \sigma_{s}^{\circ}$, the effect of $\tau_{a}$ on soil moisture retrievals with regard to the absolute soil moisture values is not straightforward. However, since $\Delta \sigma_{s}^{\circ}$ is assumed constant, apart for deserts, we can discuss the effects of $\Delta \sigma^{\circ}$ and the estimation of $\sigma_{\mathrm{dry}}^{\circ}$ on the retrieved soil moisture. As already discussed in Section IV-B.4, in cold climates, low values for the $\sigma_{\mathrm{dry}}^{\circ}$ are found most likely caused by surface conditions in winter and spring, i.e., snow cover, frozen soils, freeze-thaw cycles, and ponding water on the surface. With the dry reference being this low, it introduces a positive bias in the soil moisture retrieval, which is suggested by the relatively high soil moisture values found in boreal forests compared with soil moisture products from other satellites, e.g., SMOS and AMSR-E [65]. The work in [65] have attributed the high soil moisture values to the high porosity values that were used to calculate absolute soil moisture. However, considering the low values for $\tau_{a}$, another likely explanation is the low dry reference that is obtained during frozen conditions.

The TU-Wien products before and after the application of the current vegetation correction, i.e., the TU-Wien normalized backscatter $\left(\sigma^{\circ}(40)\right)$ and TU-Wien soil moisture $\left(\Theta_{a}\right)$, respectively, were compared with modeled surface soil moisture from ERA-Land $\left(\Theta_{\mathrm{ERA}}\right)$ (see Fig. 12). Green colors represent regions where the vegetation correction improves the correlation with ERA-Land, whereas red colors indicate areas where the correlation between $\Theta_{a}$ and $\Theta_{\mathrm{ERA}}$ is decreased as a result of the vegetation correction. The results demonstrate the positive impact of the existing vegetation correction over semiarid, temperate, and cold climates, reinforcing the previously observed high correlation coefficients between $\tau_{p}$ and $\tau_{a}$. In particular, the positive impact on soil moisture retrievals in deserts and drylands is interesting since the temporal correlation between $\tau_{a}$ and $\tau_{p}$ is negative in these areas. This suggests that either the existing vegetation correction does not correct for vegetation but corrects for dynamic land surface properties other than vegetation or that $\tau_{p}$ does not describe vegetation correctly.

Spearman R between $\Theta_{a}$ and ERA-Land soil moisture can decrease by as much as 0.4 in the northern Sahel, the southern regions in Africa, and the Ganges and Mekong floodplains and deltas, compared with Spearman R between $\sigma^{\circ}(40)$ and ERA-Land soil moisture. We suggest that this is because these regions are characterized by strong interannual variations in vegetation, whereas the correction method applies the same correction every year. Fig. 13 shows interannual variability in the $\tau_{p}$ for the period 2007-2011 based on the range between the minimum and maximum Pardé Coefficient $\triangle \mathrm{PC}[66] . \Delta \mathrm{PC}$ is calculated as the difference between the minimum and maximum monthly mean $\tau_{p}$ values normalized per year, i.e.,

$$
\Delta \mathrm{PC}=\frac{1}{m} \sum_{m=1}^{12} \frac{\max \left(\tau_{p(m, a)}\right)-\min \left(\tau_{p(m, a)}\right)}{\tau_{p(a)}}
$$

where subscript $m$ represents months, and $a$ represents years. Areas with a high coefficient are areas where the behavior of the $\tau_{p}$ differs significantly from year to year. Regions of strong interannual variability in $\tau_{p}$ can be found in Australia, the Sahel, Southern Africa, and Texas. These regions correspond with regions where the $\Theta_{a}$ shows lower correlations to $\Theta_{\text {ERA }}$ than the $\sigma^{\circ}(40)$. In these regions, interannual variability is not only found in the mean or maximum of the vegetation but also in the timing, e.g., where vegetation growth is strongly dependent on sporadic rainfall events and hence the timing of maximum vegetation cover is highly variable.

Fig. 14 shows the results of the interannual variability test, with the difference in the correlation coefficient between modeled soil moisture $\Theta_{\mathrm{ERA}}$ and the soil moisture product using the $\tau_{a}$ as a correction, $\Theta_{a}$, and the soil moisture product using $\tau_{p}$ as a correction $\Theta_{\tau_{p}}$. Fig. 14 is very similar to Fig. 12, but in more temperate and continental climates, such as in Europe and North America, the use of $\tau_{p}$ deteriorates the soil moisture 


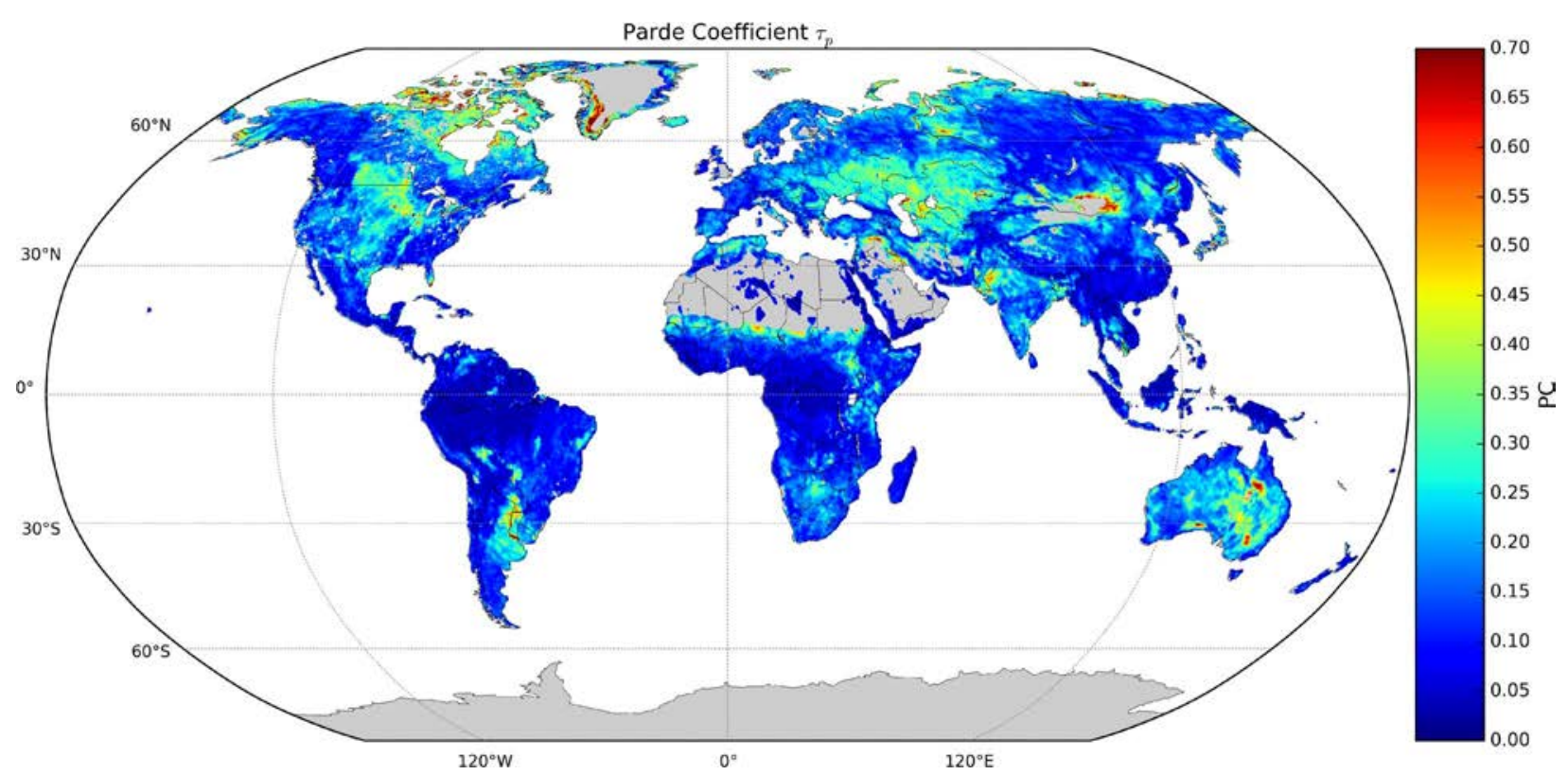

Fig. 13. $\triangle \mathrm{PC}$ over the normalized monthly differences of $\tau_{p}$, where red areas represent high interannual variability.

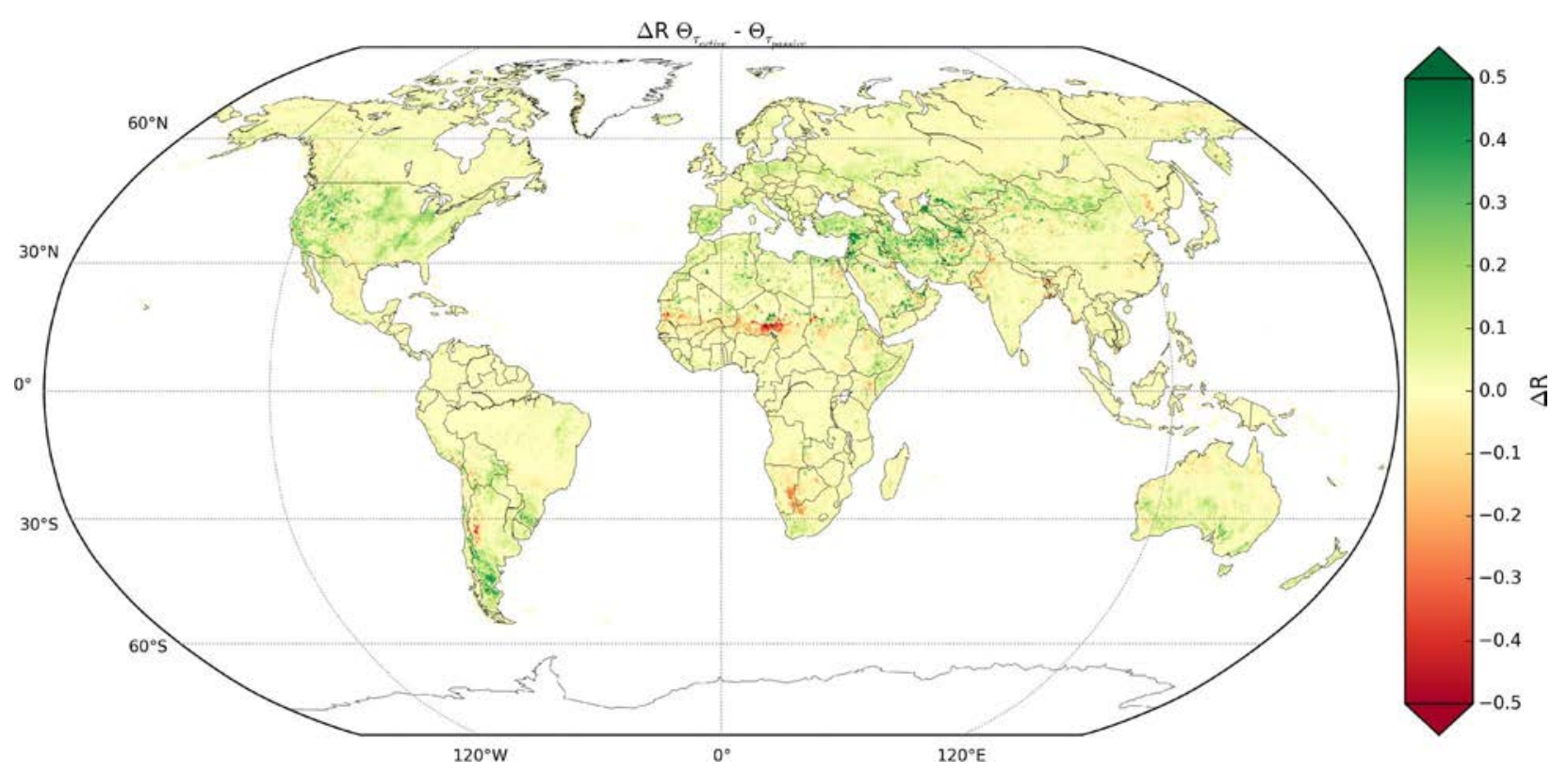

Fig. 14. Difference in Spearman rank correlation coefficients between $\Theta_{a}$ and $\Theta_{\mathrm{ERA}}$ and $\Theta_{\tau_{p}}$ and $\Theta_{\mathrm{ERA}}$, where $\tau_{a}$ is substituted by $\tau_{p}$. Negative values (in red) indicate areas where the correlation between $\Theta_{\tau_{p}}$ and $\Theta_{\mathrm{ERA}}$ is higher than between $\Theta_{a}$ and $\Theta_{\mathrm{ERA}}$.

retrieval with lowering the correlation coefficients with as much as 0.5. Areas such as the Sahel, which are characterized by high interannual variability in vegetation dynamics show significantly higher correlations when using $\Theta_{\tau_{p}}$. Fig. 15 shows the histograms of relative frequency of $\Delta \mathrm{PC}$ for points where $\Theta_{\tau_{p}}$ outperforms $\Theta_{a}$ when correlated to $\Theta_{\mathrm{ERA}}(\Delta \mathrm{R}<-0.1)$ and when $\Theta_{a}$ correlates better to $\Theta_{\mathrm{ERA}}(\Delta \mathrm{R}>0.1)$. The histogram shows that points where $\Theta_{\tau_{p}}$ outperforms $\Theta_{a}$ correspond to areas with a high $\triangle \mathrm{PC}$, i.e., to areas with high interannual variability. In addition, a Mann-Whitney test was performed which confirmed a significant difference between $\triangle \mathrm{PC}$ of areas where $\Theta_{\tau_{p}}$ performed better, characterized by a higher $\Delta P C$, and areas where $\Theta_{a}$ performed better, characterized by a low $\Delta$ PC. It appears that in areas with no significant interannual variability in vegetation dynamics, the seasonally fixed vegetation correction shows similar results or even outperforms the $\Theta_{\tau_{p}}$. For these regions, the characterization of vegetation and roughness is better by the existing vegetation correction than by the $\tau_{p}$.

\section{CONCLUSION}

This paper has analyzed the vegetation correction method of the TU-Wien soil moisture retrieval algorithm for active microwave observations and its impact on the final soil moisture product. To verify spatiotemporal characteristics of the vegetation characterization with respect to a vegetation product 


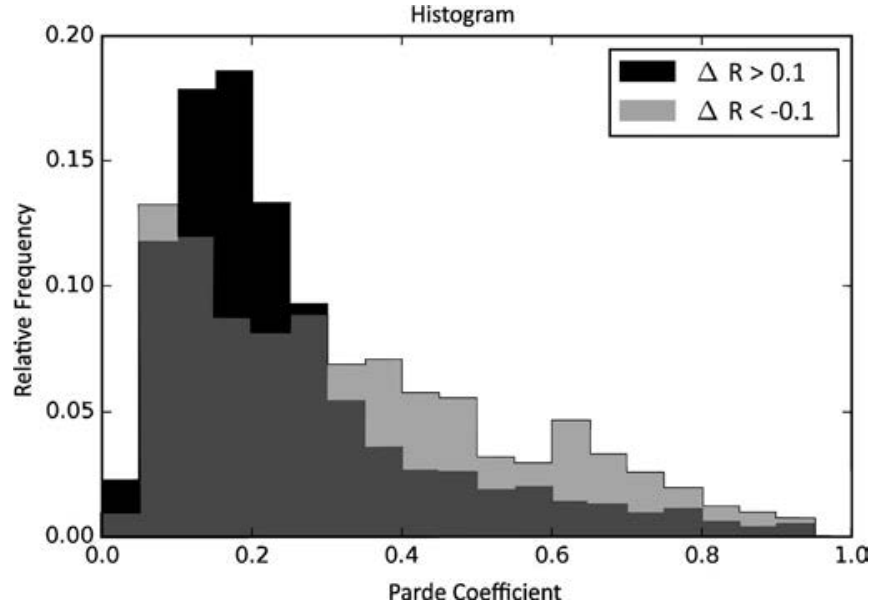

Fig. 15. Relative frequency of $\triangle \mathrm{PC}$ for points where when compared to ERA-Land $\Theta_{\tau_{p}}$ outperforms $\Theta_{a}(\Delta \mathrm{R}<-0.1)$ in pink purple and where $\Theta_{a}$ outperforms $\Theta_{\tau_{p}}(\Delta \mathrm{R}>0.1)$ in blue.

from passive microwave observations, we first converted it into vegetation optical depth using a water-cloud model. On average, mean values of the newly derived $\tau_{a}$ are 0.15 lower than mean values from $\tau_{p}$ retrieved using LPRM from passive microwave observations. This can be attributed to the underestimation of $\Delta \sigma_{s}^{\circ}$. Over boreal forests, $\tau_{a}$ is even lower, which can potentially be explained by the estimation of the dry reference over cold climates. Apart from the low values in boreal forests, $\tau_{a}$ shows very similar spatial patterns as $\tau_{p}$ and the retrieval of $\tau_{a}$ is not hampered by the assumption that $\Delta \sigma_{s}^{\circ}$ does not vary spatially. High temporal correlation coefficients are found between $\tau_{a}$ and $\tau_{p}$ in temperate and continental climates, apart from areas with open water. In particular, in semi-arid, temperate, and cold climates $\tau_{a}$ shows potential to monitor vegetation. In arid regions and in areas with dry hot summers, low or even negative correlations with the $\tau_{p}$ were observed. These are likely due to volume scattering effects or apparent soil roughness changes in dry soils. However, in these areas, the effect of vegetation on the soil moisture retrieval is minimal, and the vegetation correction does not negatively impact the quality of the soil moisture product itself.

In areas where there is high interannual variability in vegetation dynamics, the soil moisture product is negatively affected by the fixed year-to-year vegetation correction, although the $\tau_{a}$ itself is highly correlated to $\tau_{p}$. Substituting the existing correction for a dynamic correction based on the $\tau_{p}$ demonstrates that the soil moisture product is improved with respect to soil moisture from ERA-Land in areas with high interannual variability in vegetation dynamics. Consequently, the importance of a dynamic from-year-to-year varying vegetation correction in soil moisture retrievals is confirmed in this paper. This is particularly valuable information for the algorithm development of new soil moisture missions such as SMAP and Sentinel-1 and the improvement of the TU-Wien soil moisture retrieval itself. With regard to the latter, research is ongoing to develop a dynamic vegetation correction from ASCAT active microwave observations in order to provide a more robust and accurate soil moisture product. Based on the results of this paper, it is expected that the new dynamic correction will improve the soil moisture retrieval particularly in drylands and deserts and regions with high interannual variability in vegetation.

\section{ACKNOWLEDGMENT}

The authors would like to thank E. Dutra and C. Albergel from ECMWF; M. Langer from ZAMG for providing ERA-Land soil moisture data; NASA for providing GLDASNOAH precipitation data; the University of Veterinary Medicine, Vienna, Austria, for providing Koppen-Geiger climate maps; N. Andela and J. L. Salinas for their valuable input on interannual vegetation dynamics, wildfires, and perturbation models; and the reviewers for their comments and valuable feedback.

\section{REFERENCES}

[1] W. Dorigo et al., "Evaluation of the ESA CCI soil moisture product using ground-based observations," Remote Sens. Environ., vol. 162, pp. 380-395, Jun. 2015.

[2] C.-H. Su, D. Ryu, R. I. Young, A. W. Western, and W. Wagner, "Inter-comparison of microwave satellite soil moisture retrievals over the Murrumbidgee Basin, southeast Australia," Remote Sens. Environ., vol. 134, pp. 1-11, 2013.

[3] C. Albergel et al., "Evaluation of remotely sensed and modeled soil moisture products using global ground-based in situ observations," Remote Sens. Environ., vol. 118, pp. 215-226, 2012.

[4] L. Brocca et al., "Soil moisture estimation through ASCAT and AMSRE sensors: An intercomparison and validation study accross Europe," Remote Sens. Environ., vol. 115, no. 12, pp. 3390-3408, Dec. 2011.

[5] Y. Kerr et al., "The SMOS soil moisture retrieval algorithm," IEEE Trans. Geosci. Remote Sens., vol. 50, no. 5, pp. 1384-1403, May 2012.

[6] M. Owe, R. de jeu, and T. Holmes, "Multisensor historical climatology of satellite-derived global land surface moisture," J. Geophys. Res.-Earth Surface, vol. 113, no. F1, 2008, Art. ID F01002.

[7] S.-B. Kim et al., "Models of L-band radar backscattering coefficients over global terrain for soil moisture retrieval," IEEE Trans. Geosci. Remote Sens., vol. 52, no. 2, pp. 1381-1396, Feb. 2014.

[8] S.-B. Kim et al., "Soil moisture retrieval using time-series radar observations over bare surfaces," IEEE Trans. Geosci. Remote Sens., vol. 50, no. 5, pp. 1853-1863, May 2012.

[9] W. Wagner, G. Lemoin, and H. Rott, "A method for estimating soil moisture from ERS scatterometer and soil data," Remote Sens. Environ., vol. 70, no. 2, pp. 191-207, 1999.

[10] V. Naeimi, K. Scipal, Z. Bartalis, S. Hasenauer, and W. Wagner, "An improved soil moisture retrieval algorithm for ERS and metop scatterometer observations," IEEE Trans. Geosci. Remote Sens., vol. 47, no. 7, pp. 1999-2013, Jul. 2009.

[11] R. van der Schalie et al., "SMOS soil moisture retrievals using the land parameter retrieval model: Evaluation over the Murrumbidgee Catchment, southeast Australia," Remote Sens. Environ., vol. 163, pp. 70-79, Jun. 2015.

[12] R. M. Parinussa, T. R. H. Holmes, N. Wanders, W. A. Dorigo, and R. A. M. de Jeu, "A preliminary study toward consistent soil moisture from AMSR2," J. Hydrometeorol., vol. 16, no. 2, pp. 932-947, Dec. 2014.

[13] A. Meesters, R. de Jeu, and M. Owe, "Analytical derivation of the vegetation optical depth from the microwave polarization difference index," IEEE Geosci. Remote Sens. Lett., vol. 2, no. 2, pp. 121-123, Apr. 2005.

[14] J. Pulliainen, K. Heiska, J. Hyyppa, and M. Hallikainen, "Backscattering properties of boreal forests at the C- and X-bands," IEEE Trans. Geosci. Remote Sens., vol. 32, no. 5, pp. 1041-1050, Sep. 1994.

[15] J. Pulliainen, P. Mikhela, M. Hallikainen, and J.-P. Ikonen, "Seasonal dynamics of C-band backscatter of boreal forests with applications to biomass and soil moisture estimation," IEEE Trans. Geosci. Remote Sens., vol. 34, no. 3, pp. 758-770, May 1996.

[16] W. Wagner, G. Lemoine, M. Borgeaud, and H. Rott, "A study of vegetation cover effects on ERS scatterometer data," IEEE Trans. Geosci. Remote Sens., vol. 37, no. 2, pp. 938-948, Mar. 1999.

[17] N. Andela, Y. Y. Liu, A. I. J. M. van Dijk, R. A. M. de Jeu, and T. R. McVicar, "Global changes in dryland vegetation dynamics assessed by satellite remote sensing: Comparing a new passive microwave vegetation density record with reflective greenness data," Biogeosciences, vol. 10, no. 10, pp. 6657-6676, 2013.

[18] Y. Y. Liu, R. A. M. de Jeu, M. F. McCabe, J. P. Evans, and A. I. J. M. van Dijk, "Global long-term passive microwave satellite-based retrievals of vegetation optical depth," Geophys. Res. Lett., vol. 38, no. 18, p. 1, 2011. 
[19] M. O. Jones, J. S. Kimball, and L. A. Jones, "Satellite microwave detection of boreal forest recovery from the extreme 2004 wildfires in Alaska and Canada," Global Change Biol., vol. 19, no. 10, pp. 3111-3122, 2013.

[20] D. Miralles et al., "El niño-la niña cycle and recent trends in continental evaporation," Nature Climate Change, vol. 4, no. 2, pp. 122-126, 2014.

[21] L. Brocca et al., "Soil as a natural rain gauge: Estimating global rainfall from satellite soil moisture data," J. Geophys. Res.-Atmos., vol. 119, no. 9, pp. 5128-5141, 2014.

[22] C. M. Taylor, R. De Jeu, F. Guichard, P. P. Harris, and W. Dorigo, "Afternoon rain more likely over drier soils," Nature, vol. 489, pp. 282-286, 2012.

[23] C. Kuenzer, M. Schmidt, and W. Wagner, "Trend analyses of a global soil moisture time series derived from ERS-1/-2 scatterometer data: Floods, droughts and long term changes," Int. Arch. Photogramm., Remote Sens. Spat. Inf. Sci., vol. 37, pp. 1363-1368, 2008.

[24] W. Dorigo et al., "Evaluating global trends (1988-2010) in harmonized multi-satellite surface soil moisture," Geophys. Res. Lett., vol. 39, no. 18, 2012, Art. ID 118405

[25] M. Hirschi, B. Mueller, W. Dorigo, and S. Seneviratne, "Using remotely sensed soil moisture for land-atmosphere coupling diagnostics: The role of surface vs. root-zone soil moisture variability," Remote Sens. Environ., vol. 154, pp. 246-252, 2014.

[26] F. Ulaby, C. Allen, G. Eger, and E. Kanemasu, "Relating the microwave backscattering coefficient to Leaf Area Index," Remote Sens. Environ., vol. 14, pp. 113-133, 1984.

[27] M. Owe, R. de Jeu, and J. Walker, "A methodology for surface soil moisture and vegetation optical depth retrieval using the microwave polarization difference index," IEEE Trans. Geosci. Remote Sens., vol. 39, no. 8, pp. 1643-1654, Aug. 2001.

[28] T. Mo, B. J. Choudhury, T. J. Schmugge, J. R. Wang, and T. J. Jackson, "A model for microwave emission from vegetation-covered fields," J. Geophys. Res., Oceans, vol. 87, no. C13, pp. 11 229-11 237, 1982.

[29] T. R. H. Holmes, R. A. M. De Jeu, M. Owe, and A. J. Dolman, "Land surface temperature from KA band $(37 \mathrm{gHz})$ passive microwave observations," J. Geophys. Res., Atmos., vol. 114, no. D4, 2009, Art. ID d04113.

[30] Y. Y. Liu, A. I. J. M. van Dijk, M. F. McCabe, J. P. Evans, and R. A. M. de Jeu, "Global vegetation biomass change (1988-2008) and attribution to environmental and human drivers," Global Ecol. Biogeography, vol. 22, no. 6, pp. 692-705, 2013.

[31] M. O. Jones, L. A. Jones, J. S. Kimball, and K. C. McDonald, "Satellite passive microwave remote sensing for monitoring global land surface phenology," Remote Sens. Environ., vol. 115, no. 4, pp. 1102-1114, 2011.

[32] D. P. Dee et al., "The ERA-Interim reanalysis: Configuration and performance of the data assimilation system," Quart. J. Royal Meteorol. Soc., vol. 137, no. 656, pp. 553-597, 2011.

[33] G. Balsamo et al., "ERA-Interim/Land: A global land water resources dataset," Hydrol. Earth Syst. Sci. Discuss., vol. 10, no. 12, pp. 14705-14 745, 2013.

[34] M. Rodell et al., "The global land data assimilation system," Bull. Amer. Meteorol. Soc., vol. 85, no. 3, pp. 381-394, 2004

[35] M. Kottek, J. Grieser, C. Beck, B. Rudolf, and F. Rubel, "World Map of the Koeppen-Geiger climate classification updated," Meteorologische Zeitschrift, vol. 15, pp. 259-263, Jun. 2006.

[36] FAO/IIASA/ISRIC/ISSCAS/JRC. (2012) Harmonized World Soil Database (Version 1.2). [Online]. Available: http://webarchive.iiasa.ac.at/ Research/LUC/External-World-soil-database/HTML/

[37] M. C. Hansen et al., "High-resolution global maps of 21st-century forest cover change," Science, vol. 342, no. 6160, pp. 850-853, 2013.

[38] E. P. W. Attema and F. T. Ulaby, "Vegetation modeled as a water cloud," Radio Sci., vol. 13, no. 2, pp. 357-364, 1978.

[39] F. Ulaby, R. Moore, and A. Fung, Microwave Remote Sensing: Active and Passive, vol. III, Volume Scattering and Emission Theory, Advanced Systems and Applications. Dedham, MA, USA: Artech House, 1986, pp. 1797-1848.

[40] W. Wagner, "Vegetation as observed with AVHRR and ERS scatterometer-The Iberian Peninsula," Eur. Space Agency (ESA), Paris, France, vol. 424, pp. 51-56, 1998.

[41] A. Fung, W. Liu, K. Chen, and M. Tsay, "An improved IEM model for bistatic scattering from rough surfaces," J. Electromagn. Waves Appl., vol. 16 , no. 5 , pp. 689-702, 2002.

[42] H. Lievens, H. Vernieuwe, J. lvarez Mozos, B. De Baets, and N. E. C. Verhoest, "Error in radar-derived soil moisture due to roughness parameterization: An analysis based on synthetical surface profiles," Sensors, vol. 9, no. 2, pp. 1067-1093, Feb. 2009.
[43] N. Baghdadi et al., "Operational performance of current synthetic aperture radar sensors in mapping soil surface characteristics in agricultural environments: Application to hydrological and erosion modeling," Hydrol. Process., vol. 22, no. 1, pp. 9-20, Jan. 2008.

[44] F. Ulaby and P. Batlivala, "Optimum radar parameters for mapping soil moisture," IEEE Trans. Geosci. Electron., vol. 14, no. 2, pp. 81-93, Apr. 1976.

[45] F. Ulaby, P. Batlivala, and M. Dobson, "Microwave backscatter dependence on surface roughness, soil moisture, and soil texture: Part I-bare soil," IEEE Trans. Geosci. Electron., vol. 16, no. 4, pp. 286-295, Oct. 1978.

[46] E. Sano, M. Moran, A. Huete, and T. Miura, "C- and multiangle ku-band synthetic aperture radar data for bare soil moisture estimation in agricultural areas," Remote Sens. Environ., vol. 64, no. 1, pp. 77-90, 1998.

[47] N. Baghdadi, C. King, A. Bourguignon, and A. Remond, "Potential of ERS and Radarsat data for surface roughness monitoring over bare agricultural fields: Application to catchments in Northern France," Int. J. Remote Sens., vol. 23, no. 17, pp. 3427-3442, Jan. 2002.

[48] T. Jackson, H. McNairn, M. Weltz, B. Brisco, and R. Brown, "First order surface roughness correction of active microwave observations for estimating soil moisture," IEEE Trans. Geosci. Remote Sens., vol. 35, no. 4, pp. 1065-1069, Jul. 1997.

[49] M. Davidson et al., "On the characterization of agricultural soil roughness for radar remote sensing studies," IEEE Trans. Geosci. Remote Sens., vol. 38, no. 2, pp. 630-640, Mar. 2000.

[50] N. E. C. Verhoest et al., "On the soil roughness parameterization problem in soil moisture retrieval of bare surfaces from synthetic aperture radar," Sensors, vol. 8, no. 7, pp. 4213-4248, Jul. 2008.

[51] C. Matzler, "Microwave permittivity of dry sand," IEEE Trans. Geosci. Remote Sens., vol. 36, no. 1, pp. 317-319, Jan. 1998.

[52] B. Skinner, S. Porter, and P. J. , Dynamic Earth-An Introduction to Physical Geology. New York, NY, USA: Wiley, 2004.

[53] G. Nichols, Sedimentology and Stratigraphy, 2nd ed. Oxford, U.K.: Wiley-Blackwell, 2009.

[54] L. Pasolli et al., "Estimation of soil moisture in an alpine catchment with RADARSAT2 images," Appl. Environ. Soil Sci., vol. 2011, May 2011, Art. ID e175473.

[55] W. Wagner et al., "Clarifications on the comparison between SMOS, VUA, ASCAT, and ECMWF soil moisture products over four watersheds in U.S.," IEEE Trans. Geosci. Remote Sens., vol. 52, no. 3, pp. 1901-1906, Mar. 2014.

[56] W. Wagner et al., "The ASCAT soil moisture product: A review of its specifications, validation results, and emerging applications," Meteorologische Zeitschrift, vol. 22, no. 1, pp. 5-33, 2013.

[57] J. R. Wang and T. J. Schmugge, "An empirical model for the complex dielectric permittivity of soils as a function of water content," IEEE Trans. Geosci. Remote Sens., vol. GE-18, no. 4, pp. 288-295, Oct. 1980.

[58] M. Hallikainen, F. Ulaby, M. Dobson, and M. El-Rayes, "Dielectric Measurements of Soils in the 3- to 37-GHz Band Between Minus 50 Degree C and 23 Degree C," ESA IGARSS 84. Remote Sensing: From Res. Towards Operational Use, vol. 1, pp. 163-168, 1984.

[59] K. McDonald, R. Zimmermann, and J. Kimball, "Diurnal and spatial variation of xylem dielectric constant in Norway Spruce (Picea abies [L.] Karst.) as related to microclimate, xylem sap flow, and xylem chemistry," IEEE Trans. Geosci. Remote Sens., vol. 40, no. 9, pp. 2063-2082, Sep. 2002.

[60] M. C. Dobson, K. McDonald, F. T. Ulaby, and J. Way, "Effects of temperature on radar backscatter from boreal forests," in Proc. IEEE 10th Annи. IGARSS, 1990, pp. 2481-2484.

[61] K. J. Ranson, S. Saatchi, and G. Sun, "Boreal forest ecosystem characterization with SIR-C/XSAR," IEEE Trans. Geosci. Remote Sens., vol. 33, no. 4, pp. 867-876, Jul. 1995.

[62] Y. Wang, J. L. Day, F. W. Davis, and J. M. Melack, "Modeling L-band radar backscatter of Alaskan boreal forest," IEEE Trans. Geosci. Remote Sens., vol. 31, no. 6, pp. 1146-1154, Nov. 1993.

[63] A. Bartsch, R. A. Kidd, W. Wagner, and Z. Bartalis, "Temporal and spatial variability of the beginning and end of daily spring freeze/thaw cycles derived from scatterometer data," Remote Sens. Environ., vol. 106, no. 3, pp. 360-374, Feb. 2007.

[64] B. T. Gouweleeuw, A. I. J. M. van Dijk, J. P. Guerschman, P. Dyce, and M. Owe, "Space-based passive microwave soil moisture retrievals and the correction for a dynamic open water fraction," Hydrol. Earth Syst. Sci., vol. 16, no. 6, pp. 1635-1645, 2012.

[65] A. Al-Yaari et al., "Global-scale comparison of passive (SMOS) and active (ASCAT) satellite based microwave soil moisture retrievals with soil moisture simulations (MERRA-Land)," Remote Sens. Environ., vol. 152, pp. 614-626, Sep. 2014. 
[66] A. Viglione et al., "Comparative assessment of predictions in ungauged basins-Part 3: Runoff signatures in Austria," Hydrol. Earth Syst. Sci., vol. 17, no. 6, pp. 2263-2279, 2013.

[67] A. Beaudoin, T. Le Toan, and Q. Gwyn, "SAR observations and modeling of the C-band backscatter variability due to multiscale geometry and soil moisture," IEEE Trans. Geosci. Remote Sens., vol. 28, no. 5, pp. 886-895, Sep. 1990.

[68] M. S. Moran, D. C. Hymer, J. Qi, and Y. Kerr, "Comparison of ERS-2 SAR and Landsat TM imagery for monitoring agricultural crop and soil conditions," Remote Sens. Environ., vol. 79, no. 2/3, pp. 243-252, Feb. 2002.

[69] R. Bindlish and A. P. Barros, "Multifrequency soil moisture inversion from SAR measurements with the use of IEM," Remote Sens. Environ., vol. 71, no. 1, pp. 67-88, Jan. 2000.

[70] Y. Oh, K. Sarabandi, and F. Ulaby, "An empirical model and an inversion technique for radar scattering from bare soil surfaces," IEEE Trans. Geosci. Remote Sens., vol. 30, no. 2, pp. 370-381, Mar. 1992.

[71] S. Peischl et al., "The AACES field experiments: SMOS calibration and validation across the murrumbidgee river catchment," Hydrol. Earth Syst. Sci., vol. 16, no. 6, pp. 1697-1708, 2012.

[72] J. Wang, P. O’Neill, T. Jackson, and E. T. Engman, "Multifrequency measurements of the effects of soil moisture, soil texture, and surface roughness," IEEE Trans. Geosci. Remote Sens., vol. GE-21, no. 1, pp. 44-51, Jan. 1983.

[73] J. lvarez Mozos, N. E. Verhoest, A. Larranaga, J. Casali, and M. GonzalezAudicana, "Influence of surface roughness spatial variability and temporal dynamics on the retrieval of soil moisture from SAR observations," Sensors, vol. 9, no. 1, pp. 463-489, Jan. 2009.

[74] E. E. Sano, A. R. Huete, D. Troufleau, M. S. Moran, and A. Vidal, "Relation between ERS-1 synthetic aperture radar data and measurements of surface roughness and moisture content of rocky soils in a semiarid rangeland," Water Resources Res., vol. 34, no. 6, pp. 1491-1498, Jun. 1998.

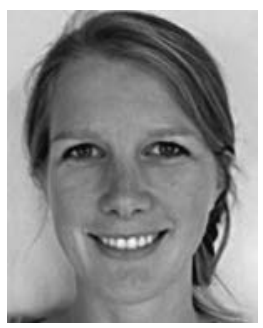

Mariette Vreugdenhil received the B.Sc. degree in earth sciences and the M.Sc. degree in applied environmental geosciences with an emphasis on remote sensing from Vrije Universiteit Amsterdam, Amsterdam, The Netherlands, in 2009 and 2011, respectively. She is currently working toward the Ph.D. degree in remote sensing with the Centre for Water Resource Systems and Department of Geodesy and Geoinformation, Vienna University of Technology, Vienna, Austria.

For her master thesis, she participated in the calibration and validation campaign of ESA's SMOS satellite in Australia (AACES). She focuses on the parameterization of vegetation in soil moisture retrievals from both active and passive microwave remote sensing observations and on calibration and validation. She is responsible for the installation and maintenance of an in situ soil moisture network in Austria, which functions as a validation site for new soil moisture satellites. Her research interests include microwave remote sensing of soil moisture and vegetation.

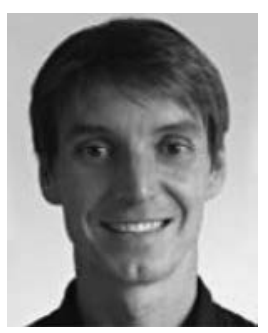

Wouter A. Dorigo received the M.Sc. degree in physical geography with an emphasis on remote sensing from Utrecht University, Uthrecht, The Netherlands, in 2000 and the Ph.D. degree in remote sensing from the Technical University of Munich, Munich, Germany, in 2008.

From 2002 to 2006 , he was with the Imaging Spectroscopy Group, German Remote Sensing Data Centre, German Aerospace Center. Since 2007, he has been working as a Researcher, a Lecturer, and a Scientific Project Coordinator with the Institute of Photogrammetry and Remote Sensing, Vienna University of Technology, Vienna, Austria. Using Earth observation data, he tries to understand and quantify the dynamics and interactions of vegetation and the water cycle in a changing climate. He is the author and coauthor of more than 60 publications in refereed journal papers and conference proceedings. His main research interests include remote sensing of soil moisture and vegetation. Within these themes, he focuses on geophysical parameter retrieval through physical and semiempirical methods, calibration and validation, process automation, upscaling and downscaling, image classification, data merging, and time series analysis.

Dr. Dorigo received the 2015 Science Award from Vienna University of Technology.

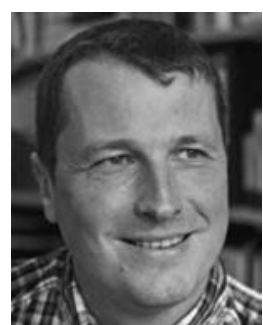

Wolfgang Wagner (M'98-SM'07) was born in Wels, Austria, in 1969. He received the Dipl-Ing. (M.Sc.) degree in physics and the Dr.techn. (Ph.D.) degree in remote sensing, both with excellence, from Vienna University of Technology, Vienna, Austria, in 1995 and 1999, respectively.

In support of his master and Ph.D. studies, he received fellowships to carry out research at the University of Bern, Atmospheric Environment Service Canada, NASA Goddard Space Flight Center, European Space Agency, and the Joint Research Centre of the European Commission. From 1999 to 2001, he was with the German Aerospace Agency (DLR). In 2001, he was appointed as a Professor for remote sensing in Vienna University of Technology, Vienna, Austria. Since 2012, he has been the Head of the Department of Geodesy and Geoinformation, Vienna University of Technology, where he is also a Cofounder and Head of Science of the Earth Observation Data Centre for Water Resources Monitoring. $\mathrm{He}$ focuses on active remote sensing techniques, in particular scatterometry, SAR and full-waveform airborne laser scanning. His main research interests include geophysical parameter retrieval techniques for remote sensing data and application development.

Dr. Wagner is a member of the Science Advisory Groups for Sentinel-1 (ESA), METOP ASCAT, and METOP-SG SCA (EUMETSAT and ESA), and a member of the GCOS/GTOS/WCRP Terrestrial Observation Panel for Climate (TOPC). He served as ISPRS Commission VII President (2008-2012) from 2008 to 2012, and as an Editor-in-Chief of the open access journal Remote Sensing from 2009 to 2011.

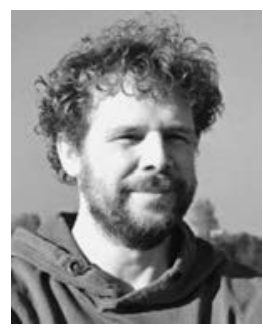

Richard A. M. de Jeu received the M.S. degree in environmental hydrology and the Ph.D. degree from the VU University Amsterdam, Amsterdam, The Netherlands, in 1996 and 2003, respectively. From 1997 to 1999, he was a Research Assistant with the VU University Amsterdam. From 1999 to 2001, he was a Research Assistant with the Goddard Space Flight Center, National Aeronautics and Space Administration, Greenbelt, MD.

Over the years, he successfully developed several satellite-derived data products including soil moisture and evaporation. These products are widely use and accessible through the official ESA and NASA data portals. He has been involved in many projects supported by the Dutch Organization for Scientific Research, European Framework, and the European and American Space Agencies. He is currently a Managing Director with Transmissivity B.V./VanderSat B.V., Noordwijk, The Netherlands. His research interests include passive microwave radiometry and the use of this technique for hydrological applications.

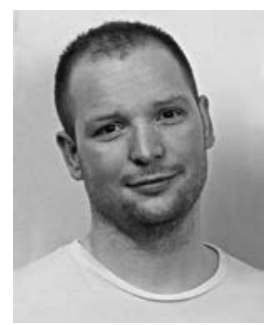

Sebastian Hahn was born in Vienna, Austria, in 1985. He received the B.Sc. degree in geodesy and geomatic engineering and the M.Sc. degree in geodesy and geophysics from Vienna University of Technology, Vienna, in 2009 and 2011, respectively. $\mathrm{He}$ is currently working toward the Ph.D. degree with the Vienna University of Technology.

Since April 2010, he has been a Project Assistant with the Department of Geodesy and Geoinformation Research Group Remote Sensing, Vienna University of Technology. He is currently one of the key developers for the software package WARP (Soil Water Retrieval Package), which represents the implementation of Vienna University of Technology's soil moisture retrieval model. As a developer, he is focused on software design, multiprocessing, model calibration, and algorithmic improvements, which is in light of his Ph.D. studies. His main research interests include remote sensing over land using active microwave instruments, active soil moisture retrieval algorithms, and software development and validation of soil moisture products.

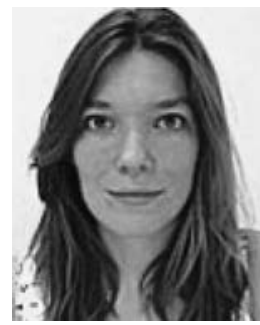

Margreet J. E. van Marle received the Bachelor's degree in biomedical sciences and the Master's degree in ecohydrology in 2009 and 2012, respectively. She is currently working toward the Ph.D. degree with Vrije Universiteit Amsterdam, Amsterdam, The Netherlands, focusing on historical forest losses and fire emissions.

Her research interests include ecology and disturbances within ecosystems, and global change, preferably with the use of remote sensing. 